\title{
The Abused Inhalant Toluene Impairs Medial Prefrontal Cortex Activity and Risk/Reward Decision-Making during a Probabilistic Discounting Task
}

\author{
Kevin M. Braunscheidel, ${ }^{1}$ Michael P. Okas, ${ }^{1}$ Michaela Hoffman, ${ }^{2}$ Patrick J. Mulholland, ${ }^{1,2}{ }^{\mathbb{C}}$ Stan B. Floresco, ${ }^{3}$ \\ and $\oplus^{\circ J o h n ~ J . ~ W o o d w a r d ~}{ }^{1,2}$ \\ ${ }^{1}$ Department of Neuroscience, ${ }^{2}$ Department of Psychiatry and Behavioral Sciences, Addiction Sciences Division, Medical University of South Carolina, \\ Charleston, South Carolina 29425, and ${ }^{3}$ Department of Psychology and Djavad Mowafaghian Centre for Brain Health, University of British Columbia, \\ Vancouver, British Colombia V6T 1Z4, Canada
}

Inhalant (e.g., toluene) misuse is linked to behavioral and cognitive deficits in humans, yet preclinical studies of the effect of inhalants on higher-order cognition are limited. We addressed this gap in the literature by examining the effect of toluene vapor exposure on risk/ reward decision-making in male and female Sprague-Dawley rats using a probabilistic discounting task. In this task, rodents chose a risky/large reward or a safe/small reward, with the odds of risky reinforcement descending or ascending throughout the test session. We observed a dose-dependent, sex-independent deficit in behavioral flexibility during probabilistic discounting caused by acute toluene exposure. Rats exposed to toluene vapor during adolescence and tested as adults performed comparably to air-treated controls and were susceptible to the effects of an acute toluene challenge. These behavioral flexibility deficits observed suggests dysfunctional medial prefrontal cortex (mPFC) activity. To address this hypothesis, we virally expressed the genetically encoded calcium sensor GCaMP6f in glutamatergic $\mathrm{mPFC}$ neurons and monitored calcium transients in real-time using in vivo fiber photometry. mPFC activity peaked before either lever press during free-choice trials in toluene- and air-treated animals. During forced-choice trials, GCaMP6f transients shifted from pre-risky to pre-safe choice, an effect mitigated by acute toluene exposure. mPFC activity decreased during rewarded trials, with larger decreases following risky/large wins compared with safe/small wins. Toluene-treated animals also had decreased mPFC activity during rewarded trials, but there was no distinction between risky/large wins and safe/small wins. These results provide physiological evidence for mPFC-dependent behavioral deficits caused by toluene.

Key words: adolescence; behavioral flexibility; drugs of abuse; GCaMP; inhalants; prelimbic cortex

\section{Significance Statement}

Inhalants (e.g., toluene) are an understudied class of drugs of abuse that cause devastating behavioral and cognitive deficits in humans. Understanding the neurobiological interactions of toluene vapor using animal models is important for developing effective treatment strategies for inhalant addicts. Here we find that toluene vapor reduces behavioral flexibility in rodents making risk/reward-based decisions. The medial prefrontal cortex (mPFC) drives behavioral flexibility during this type of decisionmaking and we show that toluene reduces the ability of mPFC neurons to track optimal choices as reward probabilities change. Toluene also reduces these neurons' ability to distinguish between small and large rewards. A combination of these factors likely leads to the impaired performance in probabilistic discounting following acute toluene exposure.

\section{Introduction}

Volatile organic solvents like toluene induce euphoria and intoxication when inhaled at high concentrations (Balster et al., 2009;
Gigengack, 2014). Their inclusion in common household products make inhalants easily accessible, likely contributing to an increasing rate of use among adolescent populations and a signif- 
icant adult lifetime prevalence (9.7\%) in the United States alone (Wu and Ringwalt, 2006; Johnston et al., 2018). Inhalant users go on to develop personality, mood, anxiety, and substance use disorders at higher rates than non-inhalant users (Wu and Howard, 2007; Howard et al., 2008; Marín-Navarrete et al., 2018). These comorbidities could develop via toluene-induced deficits in frontocortical function, resulting in reduced executive control observed in inhalant addicts (Howard et al., 2008; Dingwall et al., 2011; Takagi et al., 2011; Scott and Scott, 2014; Yuncu et al., 2015).

Preclinical models of toluene intoxication report that acute exposure to toluene impairs simple behaviors such as locomotion and object recognition (Batis et al., 2010; Huerta-Rivas et al., 2012; Montes et al., 2017). Deficits in more complex forms of cognition that are mediated by the medial prefrontal cortex (mPFC) have also been observed following chronic exposure to toluene vapor, despite varying lengths of abstinence (Baydas et al., 2005; Dick et al., 2014; Furlong et al., 2016; Braunscheidel et al., 2017). These effects may be mediated in part by neurophysiological perturbations within the frontal lobes, as previous work in our lab has shown that toluene causes long-term depression of AMPA currents in mPFC neurons (Beckley and Woodward, 2011).

Considerably less is known regarding the effects of inhalants on evaluative processes involving decisions under conditions of uncertainty or risk. One way to assess these functions in rats is with a probabilistic discounting task. In this task, rats are trained to choose between two levers, one a small, certain "safe" reward that always delivers a smaller reward, whereas the other delivers a large, uncertain "risky" reward under varying schedules of reinforcement probability. The neural circuitry that mediates this form of decision-making has been studied in some detail and includes the basolateral amygdala, nucleus accumbens shell, lateral habenula, medial orbitofrontal cortex, and notably, the mPFC (Ghods-Sharifi et al., 2009; St. Onge and Floresco, 2010; Stopper and Floresco, 2011, 2014; Stopper et al., 2014). Pharmacological inactivation of the mPFC impairs flexible decisionmaking on this task, in that rats are slower to update choice biases as reward probabilities change (St. Onge and Floresco, 2010). This profile is distinct from those induced by inactivation of cortical or subcortical brain regions mentioned above. Given these considerations, the present study used a probabilistic discounting task to test the hypothesis that acute toluene exposure induces a hypoactive $\mathrm{mPFC}$, leading to behavioral inflexibility during probabilistic discounting. To identify toluene-induced changes in $\mathrm{mPFC}$ activity during the task, we virally expressed the genetically encoded calcium sensor GCaMP6f in glutamatergic mPFC neurons and monitored calcium transients in real-time using in vivo fiber photometry while rats performed the task. Our results provide physiological evidence for the mPFC's theorized role in updating expected values of actions and implicate mPFC dysfunction in the decision-making deficits caused by toluene.

\section{Materials and Methods}

Animals. Sprague-Dawley Rats [ 45 male, 34 female, postnatal day (P)32 on arrival; Envigo RMS] were housed in pairs in polypropylene cages on a reverse light cycle (lights off at 09:00) in a climate-controlled room with food and water delivered ad libitum. At $\sim \mathrm{P} 60$, rodents were food restricted to maintain $85-95 \%$ of their free-feeding weight (weight at time of testing: males, 275-300 g; females, 200-230 g). All procedures were performed in compliance with Medical University of South Carolina IACUC protocols. The behavioral training and testing schedule is outlined in Figure $1 A$.

Lever-press training. Rats were habituated to a reward of $20 \%$ sweetened condensed milk (SCM), by giving them ad libitum access to $10 \mathrm{ml}$
SCM for $2 \mathrm{~d}$ before operant training. Over the course of two phases, rats (P60-P70) were trained to lever press in operant chambers (Med Associates) for SCM delivered to a central feeding well via a pump-activated syringe. Phase 1 ( $2-5$ d; 30 min sessions) began with one lever (left or right, pseudorandomly assigned) reinforced with $45 \mu$ l SCM on an FR1 schedule. Upon meeting criteria (50 presses for 2 consecutive days), the presented lever was switched, and rats were tested to criteria before moving on to Phase 2. Phase 2 (6-7 d; 60 min sessions) consisted of 90 trials separated by $35 \mathrm{~s}$. Each session began with an illuminated house light and $2 \mathrm{~s}$ later, the left or right lever extended in a pseudorandom order. When pressed, the lever retracted, and $45 \mu \mathrm{l} \mathrm{SCM}$ was delivered on $75 \%$ of trials. If a lever was not pressed within $20 \mathrm{~s}$, it retracted, and the trial was recorded as an omission. Following completion of 2 consecutive days of training with $<10$ omissions per session, the time to omission was reduced to $10 \mathrm{~s}$. When rats met criteria again, the lever reward probability reduced to $50 \%$. When rats met criteria a third time, a side preference test was performed as previously described (Brady and Floresco, 2015; Braunscheidel et al., 2017). Briefly, for each of 60 trials, both levers extended simultaneously and were reinforced on an FR1 schedule. A trial concluded when two presses occurred, which resulted in lever retraction for $20 \mathrm{~s}$. The preferred side was defined as the side that a rat pressed first most often across trials. Rodents then began training in the probabilistic discounting task.

Probabilistic discounting. Figure $1 B$ illustrates the probabilistic discounting procedure used to assess risk/reward decision-making in rodents (St. Onge and Floresco, 2009; Brady and Floresco, 2015). This two-lever choice task consists of a safe lever that delivered a small reward (30 $\mu \mathrm{l} \mathrm{SCM)} 100 \%$ of the time and a risky lever that delivered a large reward ( $90 \mu \mathrm{l} \mathrm{SCM}$ ) with varying probability of reinforcement. The risky lever was assigned to the non-preferred lever position as determined by the side preference test. Each session consisted of 90 trials separated into 5 blocks and each block started with 8 forced-choice trials that set the probability of reinforcement for the following 10 free-choice trials. The probability of obtaining a large reward was varied from low-to-high ("ascending") or high-to-low ("descending") with the following probabilities: 100, 50, 25, 12.5, 6.25\% (Fig. 1C). Each trial lasted $35 \mathrm{~s}$ and began with an illuminated house light and $2 \mathrm{~s}$ later levers extended into the chamber. A press on either lever caused both of them to retract and turned the house light off. On rewarded trials, reward was delivered to the central feeding well. These "wins" were paired with a discriminative cue: a flashing light above the food well to indicate whether the reward was small or large (safe win: 2 pulses, $0.35 \mathrm{~s}$ pulse width, $0.5 \mathrm{~Hz}$; risky win: 5 pulses, $0.35 \mathrm{~s}$ pulse width, $0.5 \mathrm{~Hz}$ ). On non-reinforced "loss" trials, no cue light was provided. If a lever was not pressed in $10 \mathrm{~s}$, it was recorded as an omission and the houselights were extinguished for $25 \mathrm{~s}$. Following $\sim 20 \mathrm{~d}$ of training (5-6 d per week), rats exhibited stable responding (two-way ANOVA on 3 consecutive testing days yields no block $\times$ day interaction or main effect of day, $p>0.1$ ) and were tested for probabilistic discounting following exposure to air or toluene vapor.

Toluene exposure. For acute intoxication studies, rodents underwent $2 \mathrm{~d}$ of probabilistic discounting with testing occurring $30 \mathrm{~min}$ after a brief $(15 \mathrm{~min})$ exposure to an air-filled chamber $(30 \times 30 \times 30 \mathrm{~cm}, 4 \mathrm{~L} / \mathrm{min}$; Fig. $1 D, E)$. On toluene test days, the vapor chambers were filled with toluene vapor at concentrations relevant to human solvent abuse (Brouette and Anton, 2010; Bukowski, 2001; Gmaz et al., 2012) via a sevoflurane vaporizer (Penlon; flow rate $4 \mathrm{~L} / \mathrm{min}$ ) as previously described (Wayman and Woodward, 2018). Toluene vapor concentrations within the chamber were intermittently monitored with a portable toluene gas detector (DOD Technologies). To establish a dose-effect, each rat was first tested following exposure to 10,500 ppm toluene, given 2 weeks off, retrained to baseline performance, and tested again following exposure to $6000 \mathrm{ppm}$ toluene. At these doses, rats exhibit lethargy after $\sim 10 \mathrm{~min}$ of exposure and were nearly immobile after $15 \mathrm{~min}$. Rats fully regained ambulation following $\sim 15 \mathrm{~min}$ of recovery in the home cage (K.M. Braunscheidel, M.P. Okas, J.J. Woodward, unpublished observations).

A subset of rats were exposed to a binge-like regimen of, twice daily, 15 min exposures to $10,500 \mathrm{ppm}$ toluene (12 male, 12 female) or air (12 male, 12 female) during adolescence (P39-P43) as described previously (Braunscheidel et al., 2017). Rats were then tested with the descending 
A

P53

Probabilistic Discounting

P120+

Habituation

Rats arrive

Tever Press Training (PD) Training

P60

P70

|

PD testing \pm toluene; $>1$ week

$\sim$ P98 retraining between tests

B

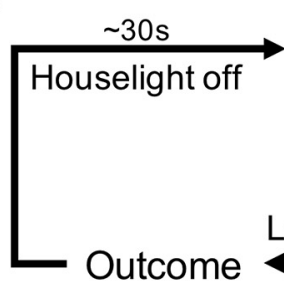

- Safe Win / Small Reward

- Risky Win / Large Reward

- Risky Loss / No Reward
D

Toluene Chamber

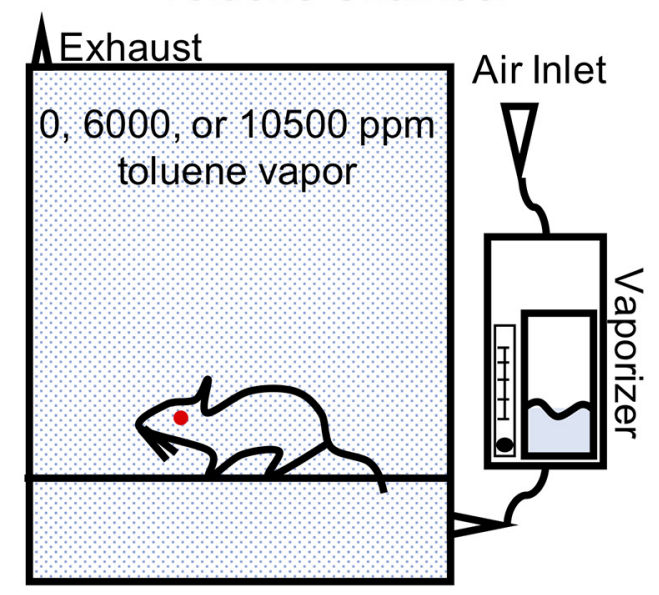

C

\begin{tabular}{|c|c|c|}
\hline Choice Type & Forced & Free \\
\hline Trials Per Block & 8 & 10 \\
\hline Probability & 100 & 100 \\
\hline of Risky & 50 & 50 \\
\hline Reward (\%) & 25 & 25 \\
\hline & 12.5 & 12.5 \\
\hline & 6.25 & 6.25 \\
\hline
\end{tabular}

E

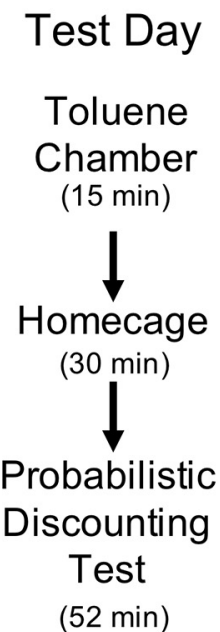

Figure 1. Probabilistic discounting training and test design. $\boldsymbol{A}$, Behavioral timeline and corresponding rat age. $\boldsymbol{B}$, Flow chart detailing a single trial of the probabilistic discounting task. $\boldsymbol{C}$, Breakdown of the 10 different behavioral blocks within the probabilistic discounting task. 0 dds were presented either in ascending or descending order. $\boldsymbol{D}$, Toluene inhalation chamber schematic. $\boldsymbol{E}$, Test day progression.

odds probabilistic discounting task during adulthood. Rodents tested on the ascending odds version were not treated with air exposures during adolescence.

Fiber photometry. A subset of 11 rodents underwent stereotaxic surgery before lever-press training. Deep anesthesia was achieved via an isoflurane vaporizer (Penlon; $1 \mathrm{~L} / \mathrm{min}, 5 \%$ induction, $2-3 \%$ maintenance) and $300 \mathrm{nl}$ of AAV1-CaMKII-GCaMP6f (Addgene) was injected into the prelimbic portion of the mPFC (AP: +2.95; ML: -0.6 ; DV: $-2.85 \mathrm{~mm}$ ). A custom-made fiber-optic ferrule (400 $\mu \mathrm{m}$ diameter patch cord in a 2. 5 $\mathrm{mm}$ ferrule; Thorlabs) was implanted at these coordinates and secured in place using dental cement (Land Dental). Postmortem inspection revealed that two rats lacked viral expression under the fiber optic ferrule, and one ferrule terminated in the anterior cingulate cortex, leaving eight rats with appropriate viral expression and ferrule placement. Rats recovered in their home cage for $7 \mathrm{~d}$ before beginning lever-press training. Following stable probabilistic discounting performance ( $\sim 5-6$ weeks), rats were tested in an operant chamber modified to permit fiber access. Rats performed in this chamber for 2 consecutive days before experimental testing and recording.

To test for an effect of our toluene exposure paradigm on baseline mPFC activity, rats were then given 1 month of home cage recovery and tested a final time in an inactive operant chamber. Probabilistic discounting test days were mimicked in that baseline testing occurred 30 min after a 15 min exposure to air or 10,500 ppm toluene (counter-balanced) with 1 week off in between testing. Calcium events were identified in
MATLAB using the findpeaks function with the following filters: MinPeakProminence $=4$, MinPeakDistance $=0.25$, and MinPeakWidth $=$ 0.5 . One rat's headcap dislodged during this test and data from this animal were not included in the analysis baseline mPFC activity.

Data were acquired using custom-built imaging equipment based on that described by the Deisseroth laboratory (Lerner et al., 2015), with modifications. Illumination was provided by 405 and $490 \mathrm{~nm}$ fiber collimated LEDs (Thorlabs; $30 \mu \mathrm{W}$ per channel) connected to a four-port fluorescence mini-cube (Doric Lenses). The combined LED output passed through a $400 \mu \mathrm{m}$ optical fiber $(0.48 \mathrm{NA})$ pigtailed to a rotary optical swivel (FRJ_1X1_PT, Doric Lenses) and connected to the implanted fiber using a ceramic sleeve or pinch connector (Thorlabs). Emission light was focused onto a photodetector (Newport, model 2151; DC low setting) and sampled at $6.1 \mathrm{kHz}$ by a RZ5P lock-in digital processor (TDT) controlled by Synapse software (TDT). Excitation light was sinusoidally modulated at $531 \mathrm{~Hz}(405 \mathrm{~nm})$ and $211 \mathrm{~Hz}(490 \mathrm{~nm})$ via software control of an LED light driver (Thorlabs). Real-time demodulated emission signals from the two channels were acquired at a frequency of $0.93084 \mathrm{kHz}$ and stored off-line for analysis. Lever-press activity and resulting output were collected using TTL inputs to the digital processor. Data were processed using custom-written functions in MATLAB (MathWorks) software. The signals for each channel were first fitted to a polynomial versus time curve and then subtracted from one another to calculate the $\Delta F / F$ time series. Video of the test sessions were 


\section{Descending Odds}

A
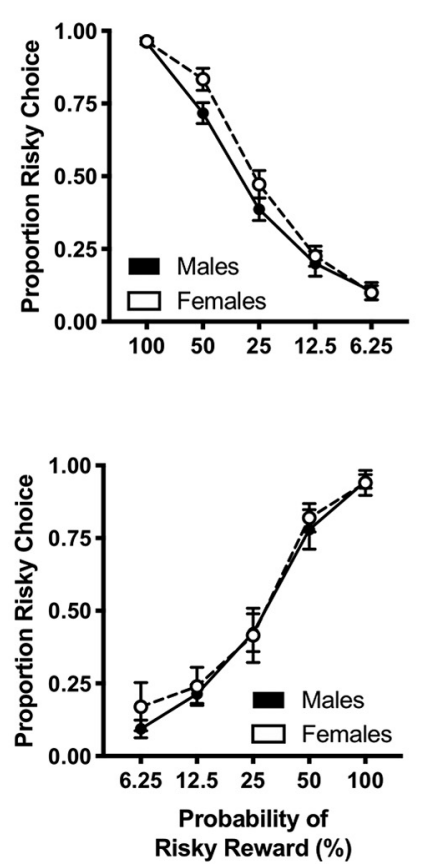

B

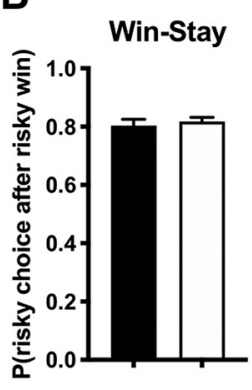

C

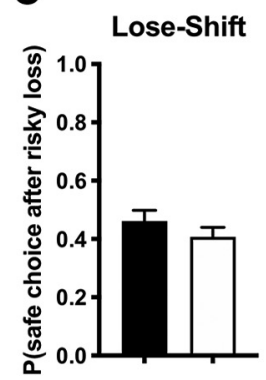

D

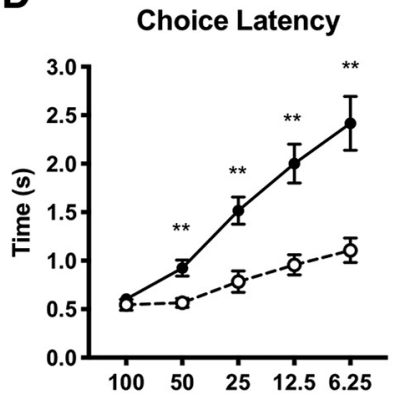

E

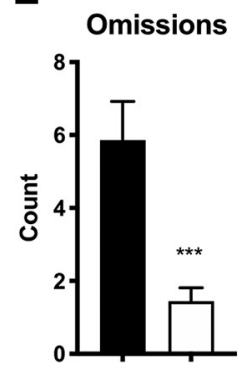

Ascending Odds
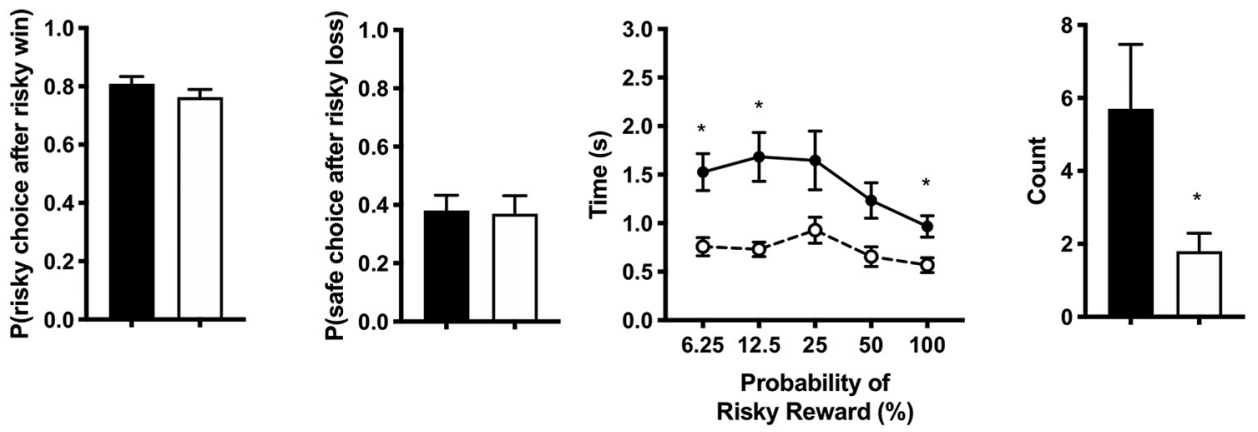

Figure 2. Male and female Sprague-Dawley rats acquire similar levels of probabilistic discounting. Rats were trained at least $20 \mathrm{~d}$ on the probabilistic discounting task with descending odds (top) or ascending odds (bottom) until responding stabilized. Performance over the final $3 \mathrm{~d}$ of training were averaged and compared with test for sex differences in baseline task performance. $\boldsymbol{A}$, Proportion of risky choice within each probability block $(\boldsymbol{B}, \boldsymbol{C})$ Choice strategy across all trials. Win-stay $(\boldsymbol{B})$ indicates choice of risky lever after risky win, whereas lose-shift $(\boldsymbol{C})$ indicates choice of safe lever after risky loss. $\boldsymbol{D}$, Time to choice selection within each probability block. Omissions across all trials $(\boldsymbol{E})$ indicate no lever press within 10 s time period. Data shown are mean \pm SEM; descending odds: all $n=12$; ascending odds: all $n=10$; two-way ANOVA and Sidak's test, ${ }^{*} p<0.05,{ }^{* *} p<0.01$. Student's $t$ test, ${ }^{*} p<0.05,{ }^{* * *} p<0.001$.

recorded using a C930e webcam (Logitech) affixed to the top of the operant chamber.

Experimental design and statistical analysis. The primary dependent variable of the probabilistic discounting test was risky lever preference, expressed as proportion risky choice (number risky lever presses/total lever presses) during each of the five behavioral blocks separated by likelihood of a rewarded risky lever press. Additional performance variables including omissions, latency to choice, win-stay (number of risky lever presses following a risky win/total number of risky wins), and loseshift (number of safe lever presses following a risky loss/total number of risky losses) were also recorded. Only free-choice trials were considered in behavioral analyses. Probabilistic discounting data were analyzed with two-way ANOVA with reward probability and toluene exposure as repeated, within-subject factors using Prism 8 (GraphPad Software). A Greenhouse-Geisser correction was applied to account for repeated measures and Dunnett's test corrected for multiple comparisons. Win-stay, loseshift, and omissions were analyzed with Sidak's multiple-comparison test.

Fiber photometry measures in air vs toluene conditions were compared with paired $t$ tests. Comparisons within treatment (i.e., air or toluene exposure) were $z$-normalized with MATLAB (MathWorks) to compare signal before and after risky and safe choices. GCaMP6f activity preceding risky versus safe lever choice during discounting was analyzed with two-way ANOVA with reward probability and choice as withinsubject factors. Sidak's multiple-comparison test was used to directly compare activity during each reward probability block. An $\alpha$ value of 0.05 was used in all analyses.

\section{Results}

Sex differences in baseline probabilistic discounting

Males and females reached similar levels of baseline

probabilistic discounting

Figure 2 summarizes baseline probabilistic discounting behavior in male and female Sprague-Dawley rats following $\sim 4$ weeks of train- ing. Males and females had similar risky lever preference (Fig. $2 \mathrm{~A}$ ) in the descending odds (two-way ANOVA, sex $\times$ block interaction: $F_{(4,88)}=1.73, p=0.15$; main effect of sex: $\left.F_{(1,22)}=2.18, p=0.15\right)$ and ascending odds tests $\left(\right.$ sex $\times$ block interaction: $F_{(4,72)}=0.22, p=$ 0.93 ; main effect of sex: $\left.F_{(1,18)}=0.26, p=0.62\right)$. Choice data were then sorted on a trial-by-trial basis to study the effect of recent outcomes on subsequent choice. Figure $2 B$ illustrates the effect of recent positive reinforcement on choice strategy, measured as the probability of choosing the risky lever following a risky win ("win-stay"). Males and females showed similar levels of win-stay behavior in the descending (Student's $t$ test, $t_{(22)}=0.54, p=0.60$ ) and ascending odds task $\left(t_{(18)}=1.26, p=0.22\right)$. Figure $2 C$ details the effect of recent negative feedback sensitivity on choice strategy, measured as the probability choosing the safe lever following a risky loss ("loseshift"). Males and females showed similar levels of lose-shift behavior in the descending (Student's $t$ test, $t_{(22)}=1.09 . p=0.29$ ) and ascending odds task $\left(t_{(18)}=0.13, p=0.89\right)$.

\section{Choice latency and omissions}

Choice latency and omission data may reflect decision speed, impulsivity and/or general motivation to lever press for reward. Females were significantly quicker than males in making a lever selection during probabilistic discounting in the descending odds task (twoway ANOVA, sex $\times$ block interaction: $F_{(4,88)}=11.0, p<0.0001$; main effect of sex: $\left.F_{(1,22)}=25.6, p<0.0001\right)$. The main effect of sex was also evident in the ascending odds task $\left(F_{(1,18)}=13.2, p=\right.$ $0.0019)$ despite the lack of a sex $\times$ block interaction $\left(F_{(4,72)}=1.630\right.$, $p=0.1761)$. Females also omitted significantly fewer trials than males during the descending (Student's $t$ test, $t_{(22)}=3.94$. $p=$ $0.0007)$ and ascending odds task $\left(t_{(18)}=2.12, p=0.048\right)$. Together, 


\section{Descending Odds}

A
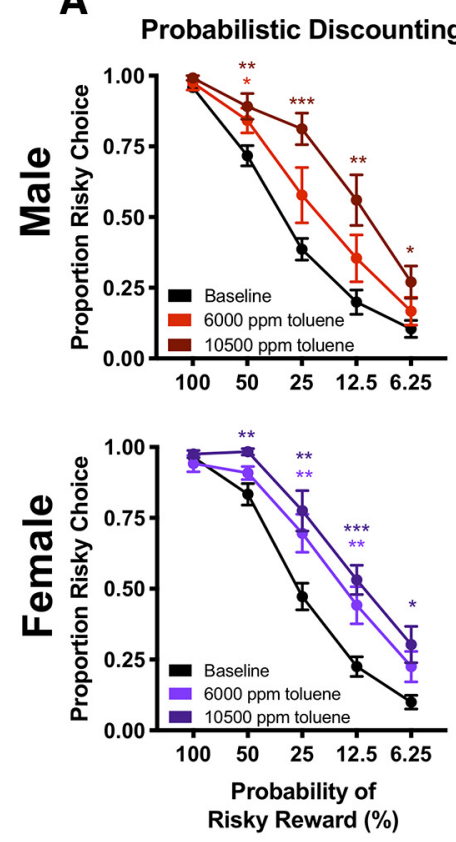

Probabilistic Discounting
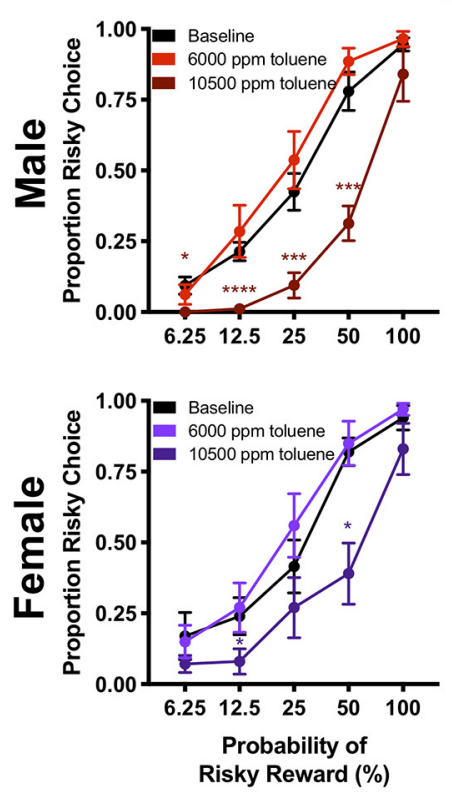

C
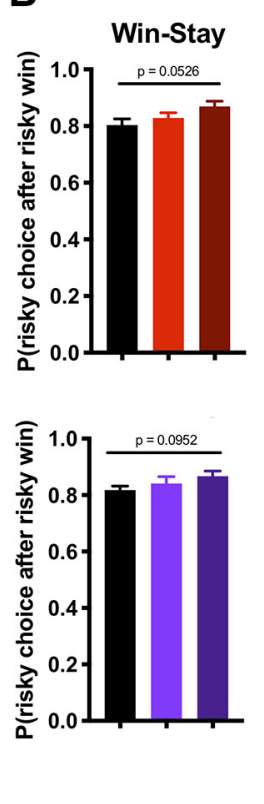

Ascending Odds
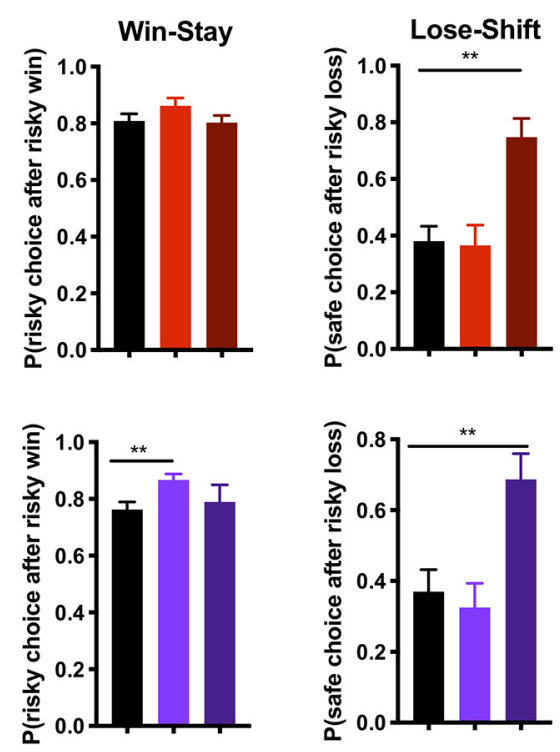

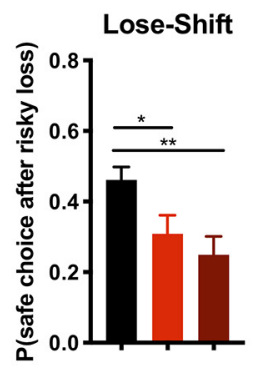

Choice Latency

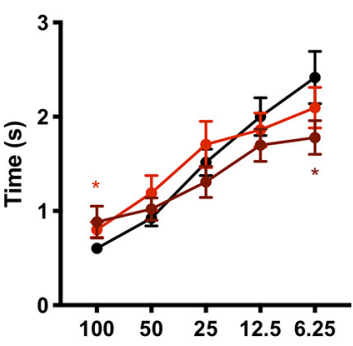

E
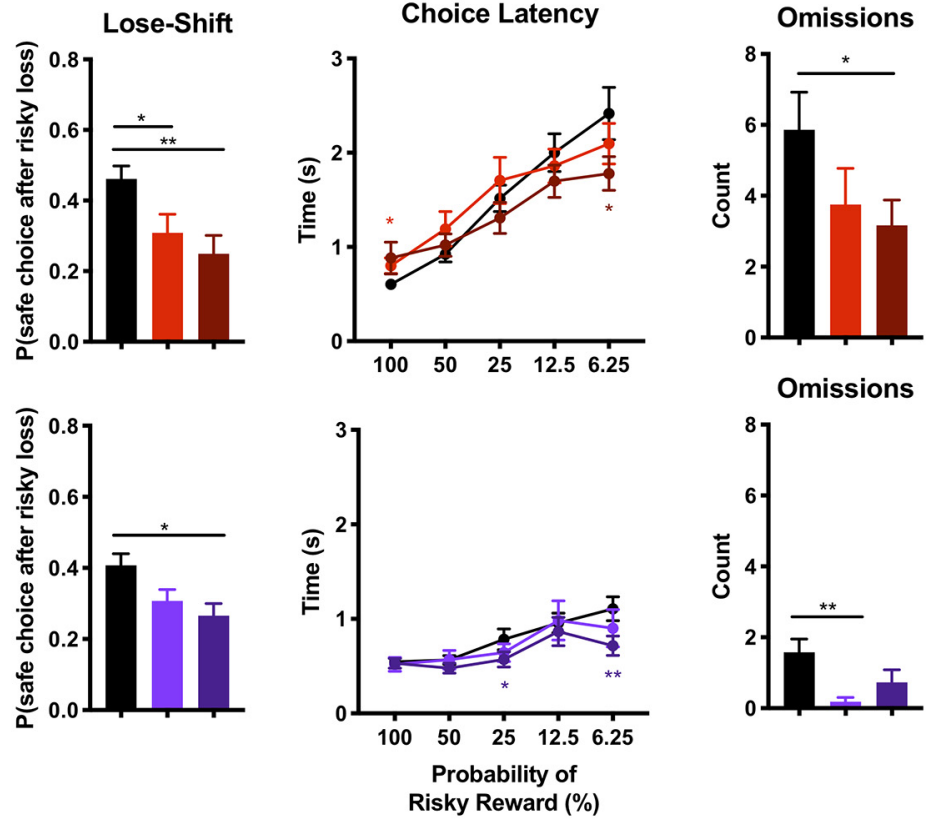

Omissions
Choice Latency
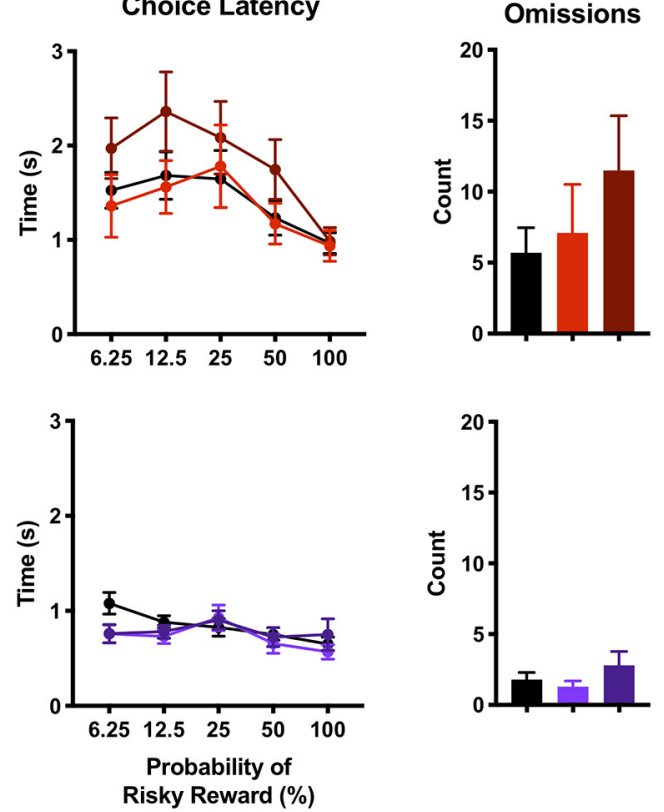

Figure 3. Toluene impairs flexible decision-making during probabilistic discounting. Male and female rats were trained at least $20 \mathrm{~d}$ on the probabilistic discounting task with descending odds (top) or ascending odds (bottom) until responding stabilized. A, Proportion of risky choice within each probability block following acute exposure to air or toluene (6000; 10,500 ppm). B, C, Choice strategy across all trials. Win-stay $(\boldsymbol{B})$ indicates choice of risky lever after risky win, whereas lose-shift $(\boldsymbol{C})$ indicates choice of safe lever after risky loss. $\boldsymbol{D}$, Time to choice selection within each probability block. Omissions across all trials $(\boldsymbol{E})$ indicate no lever press within 10 s time period. Data shown are mean \pm SEM; descending odds: all $n=12$; ascending odds: all $n=10$; two-way ANOVA and Dunnett's test comparing each dose to baseline, ${ }^{*} p<0.05,{ }^{* *} p<0.01,{ }^{* * *} p<0.001,{ }^{* * * *} p<0.0001$; colored to match dose.

these data suggest that females may be more engaged with the probabilistic discounting task than their male counterparts.

Effect of acute toluene exposure on probabilistic discounting Toluene impairs shifts in choice biases

Figure 3 shows the effect of toluene vapor on probabilistic discounting under conditions of descending (top 2 panels) or ascending odds (bottom 2 panels). Under control conditions, both males and females trained on the descending version of the task displayed a strong choice preference for the risky option during the early part of the session, when reward probabilities were relatively high, but preference gradually shifted toward the small certain option as reward probabilities decreased over a session. The opposite profile was observed in rats trained on the ascending version of the task (Fig. 3A). When odds of receiving a large reward decreased, acute exposure to toluene vapor $30 \mathrm{~min}$ before testing increased the proportion of risky choices made by male 
(Figure $3 A$, top; two-way ANOVA, drug $\times$ block interaction, main effect of drug: $\left.F_{(1.511,16.62)}=15.7, p=0.0003\right)$ and female rats (two-way ANOVA, main effect of drug: $F_{(1.746,19.20)}=16.8, p<$ $0.0001)$. Dunnett's test revealed a significant effect of toluene dose on this effect, as exposure to 10,500 ppm toluene caused a more pervasive disruption in risk preference than $6000 \mathrm{ppm}$ toluene in male rats $(10,500 \mathrm{ppm}$ vs baseline, $50,25,12.5$, and $6.25 \%$ block: all $q_{(11)}>2.77, p<0.034 ; 6000$ ppm vs baseline, $50 \%$ block, $\left.q_{(11)}=2.72, p=0.036\right)$. This dose-dependent effect was also evident in females $(10,500 \mathrm{ppm}$ vs baseline, $50,25,12.5$, and $6.25 \%$ block: all $q_{(11)}>3.13, p<0.018 ; 6000$ ppm vs baseline, 25 and $12.5 \%$ block, both $\left.q_{(11)}>3.49, p<0.010\right)$.

In contrast to these results, rats trained on the ascending version of the task and exposed to toluene vapor showed a reduction in the proportion of risky choices when odds of receiving a large reward increased during the task (Fig. 3A, bottom). This effect was observed in males (two-way ANOVA, main effect of drug: $F_{(1.981,17.83)}=29.4, p<0.0001$ ) and females (main effect of drug: $\left.F_{(1.1861,16.75)}=11.1, p=0.0010\right)$. Dunnett's test revealed a significant effect of dose of this effect in male $(10,500 \mathrm{ppm}$ vs baseline, $6.25,12.5,25$, and $50 \%$ block: $q_{(9)}>3.09, p<0.024 ; 6000$ ppm vs baseline, all blocks: $\left.q_{(9)}<1.32, p>0.38\right)$ and in female rats $\left(10,500\right.$ ppm vs baseline, 12.5 and $50 \%$ blocks: $q_{(9)}>2.75, p<$ $0.041 ; 6000$ ppm vs baseline, all blocks: all $\left.q_{(9)}<1.40, p>0.31\right)$. These findings reveal that the effect of toluene on risk preference is dependent on the order in which the odds of risky reinforcement are presented. Nonetheless, under both conditions, rats demonstrated impaired behavioral flexibility because they were slower to modify their choice biases in response to changes in probabilities of obtaining the large/risky reward.

\section{Choice strategy}

Choice data were sorted on a trial-by-trial basis to study the effect of recent outcomes on subsequent choice (Fig. $3 B, C$ ). Figure $3 B$ illustrates the effect of toluene on recent positive reinforcement, measured as win-stay behavior. Toluene $(10,500 \mathrm{ppm})$ produced a strong trend for an increase in win-stay behavior versus baseline in males when odds were presented in descending order (top; Dunnett's test, $\left.q_{(11)}=2.50, p=0.053\right)$. This trend was also observed in females (Dunnett's test, $q_{(11)}=2.16, p=0.095$ ). Interestingly, during the ascending phase of the task (bottom), $6000 \mathrm{ppm}$ toluene increased win-stay behavior in female (Dunnett's test, $q_{(9)}=4.05$, $p=0.0053$ ), but not male rats (Dunnett's test, $q_{(9)}=1.73, p=0.20$ ).

Figure $3 C$ details the effect of toluene on recent negative feedback sensitivity, measured as lose-shift behavior. Exposure to both doses of toluene vapor decreased lose-shift behavior in male (Dunnett's test, 10,500 ppm vs baseline: $q_{(11)}=3.89, p=0.0047$; 6000 ppm vs baseline: $\left.q_{(11)}=3.12, p=0.018\right)$ and female rats $\left(10,500\right.$ ppm vs baseline $\left.\mathrm{q}_{(11)}=3.17, p=0.016\right)$ when odds descended during testing (top). However, when the odds of receiving a large reward increased over the session (bottom), exposure to $10,500 \mathrm{ppm}$ toluene enhanced lose-shift behavior in both male (Dunnett's test, $\left.q_{(9)}=4.35, p=0.0034\right)$ and female rats $\left(q_{(9)}\right.$ $=3.18, p=0.020)$. Together, these data suggest that impaired flexible decision-making induced by toluene exposure is driven by perturbations in negative feedback sensitivity, and that this is exacerbated (or mitigated, depending on task) by increased sensitivity to recently rewarded actions.

\section{Choice latency and omissions}

In the descending odds version of the task, choice latency (Fig. $3 D$, top) decreased following treatment with $10,500 \mathrm{ppm}$ toluene in blocks where reinforcement was unlikely (Dunnett's test, 10,500 ppm vs baseline, $6.25 \%$ block: $\left.q_{(11)}=2.54, p=0.049\right)$ and females (Dunnett's test, 50\% block: $q_{(11)}=3.11, p=0.018,6.25 \%$ block: $\left.q_{(11)}=3.69, p=0.0066\right)$. Interestingly, exposure to $6000 \mathrm{ppm}$ toluene vapor increased choice latency in male rats during blocks when risky reinforcement was guaranteed (Dunnett's test, 100\% block: $q_{(11)}=2.62, p=0.043$; Fig. $3 D$, bottom). Toluene had no effect on choice latency in male or female rats in any block of the ascending odds version of the task (male, all $q_{(9)}<2.13, p>0.10$; female, all $q_{(9)}<1.78, p>0.18$; Fig. $2 E$ ) Toluene exposure caused a minor, but statistically significant, decrease in the number of omissions in two instance during the descending odds task (Dunnett's test, males, 10,500 ppm vs baseline: $q_{(11)}=2.58, p=0.046$; females, 6000 ppm vs baseline: $\left.q_{(11)}=3.91, p=0.0054\right)$. There were no differences in omissions detected for the ascending odds task (all $\left.q_{(9)}<1.39, p>0.32\right)$. These data suggest that toluene can decrease choice latency and promote task engagement (decreased omissions), but other factors need to be taken in to consideration (sex, duration of task, task-type) when interpreting the effect of toluene on impulsivity and general motivation.

\section{Effect of adolescent toluene exposure on probabilistic discounting in adulthood}

Probabilistic discounting training in adults is not significantly affected by adolescent exposure to toluene

Previous studies suggest that toluene abuse during adolescence can impair cognitive performance in adulthood in humans (Dingwall et al., 2011; Scott and Scott, 2014; Yuncu et al., 2015), and rodents (Dick et al., 2014; Furlong et al., 2016; Braunscheidel et al., 2017). Fig. 4-1 (available at https://doi.org/10.1523/ JNEUROSCI.1674-19.2019.f4-1) shows that acute exposure to toluene vapor during adolescence did not significantly alter risk preference of adult rats in the descending odds probabilistic discounting task during any of the first 4 weeks of training (week average). Transient increases in choice latency were observed in toluene-treated rats versus control (two-way ANOVA, main effect of treatment, males, Week 3: $F_{(1,18)}=8.99, p=0.0077$; females, Week $\left.2 F_{(1,22)}=7.90, p=0.010\right)$ but these differences were no longer significant by Week 4 (main effect of treatment, males: $F_{(1,18)}=3.43, p=0.080$; females: $\left.F_{(1,22)}=1.66, p=0.21\right)$. Likewise, a transient decrease in lose-shift behavior was detected in male rats in Week 3 (Welch's test, $t_{(17.37)}=2.36, p=0.030$ ), but this recovered by Week $4\left(t_{(17.80)}=1.35, p=0.20\right)$. Lose-shift behavior also decreased in females during Week 4 of training $\left(t_{(19.53)}=2.19, p=0.041\right)$. The average number of omissions transiently increased in female rats treated with toluene during adolescence compared with air-treated control (Week 1: $t_{(13.13)}=$ 2.58, $p=0.023$; Week 2: $\left.t_{(14.09)}=0.69, p=0.50\right)$.

\section{A history of adolescent toluene exposure does not alter the effects of} toluene on decision-making in adulthood

To test whether prior exposure to toluene may sensitize or mitigate its effect on probabilistic discounting when animals are exposed again as adults, adolescent-exposed rats were tested during adulthood following an acute exposure to 10,500 and $6000 \mathrm{ppm}$ toluene (Fig. 4A). As shown above, toluene (10,500 ppm) shifted risk preference in male (main effect of drug: $F_{(1.946,21.41)}=6.45$, $p=0.0068$; Dunnett's test, 10,500 ppm vs baseline, 50 and $25 \%$ block: both $\left.q_{(11)}>3.46, p<0.0012\right)$ and female rats $\left(F_{(1.847,20.32)}=\right.$ 7.43, $p=0.0045 ; 50,25,12.5,6.25 \%$ blocks: all $q_{(11)}>2.64, p<$ $0.042)$. Interestingly, the lower dose of toluene (6000 ppm) increased risky choice preference exclusively when reinforcement was guaranteed in male (Dunnett's test, 6000 ppm toluene vs baseline, $100 \%$ block: $\left.q_{(11)}=4.71, p=0.0012\right)$ and female rats 
A
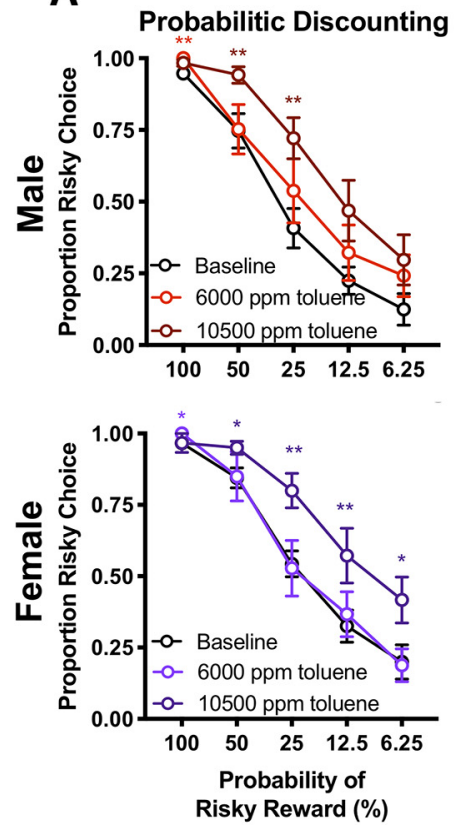

B
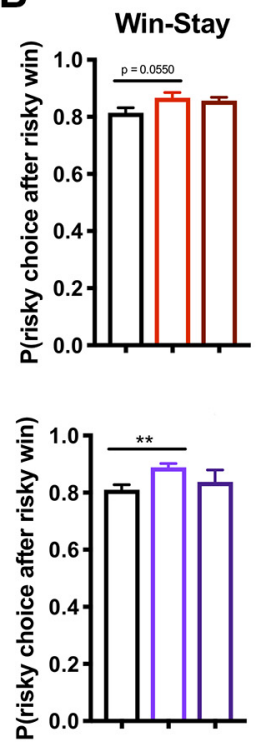

C
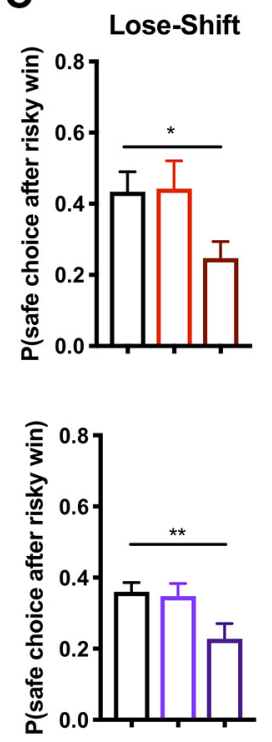

D
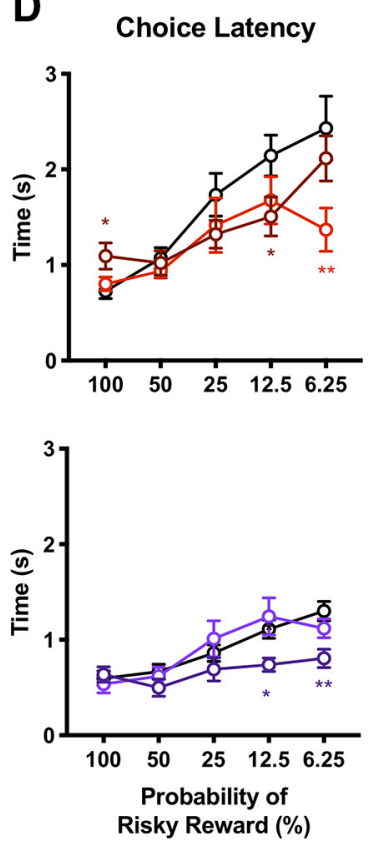

E

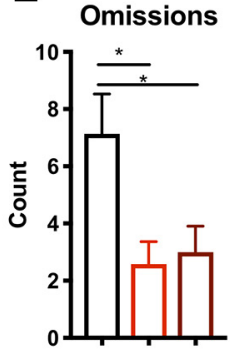

Figure 4. Toluene impairs behavioral flexibility in the probabilistic discounting task in adult rats treated with toluene vapor during adolescence. Adolescent rats were treated with a 10,500 ppm toluene for $15 \mathrm{~min}$, twice daily, over $5 \mathrm{~d}$ followed by home cage recovery until adulthood (Figure 4-1, available at https://doi.org/10.1523/JNEUROSCl.1674-19.2019.f4-1). Adult male and female rats were trained at least $20 \mathrm{~d}$ on the probabilistic discounting task with descending odds until responding stabilized. $\boldsymbol{A}$, Proportion of risky choice within each probability block following acute exposure to air or toluene $(6000 ; 10,500$ ppm). $\boldsymbol{B}, \boldsymbol{C}$, Choice strategy across all trials. Win-stay (B) indicates choice of risky lever after risky win, whereas lose-shift ( $\boldsymbol{C}$ ) indicates choice of safe lever after risky loss. $\boldsymbol{D}$, Time to choice selection within each probability block. Omissions across all trials $(\boldsymbol{E})$ indicate no lever press within $10 \mathrm{~s}$ time period. Data shown are mean \pm SEM; all $n=12 ;$ two-way ANOVA and Dunnett's test comparing each dose to baseline, ${ }^{*} p<0.05,{ }^{* *} p<0.01$, colored to match dose.

$\left(q_{(11)}=2.71, p=0.037\right.$; Fig. $\left.4 B\right)$. Although toluene increased win-stay behavior in this cohort, this was in response to the lower dose of toluene (Dunnett's test, $6000 \mathrm{ppm}$ toluene vs baseline, male: $q_{(11)}=2.48, p=0.055$; female: $q_{(11)} 3.63=$, $p=0.0074)$. Like toluene-naive rats, acute $10,500 \mathrm{ppm}$ toluene exposure decreased lose-shift behavior (Fig. 4C) in this cohort (Dunnett's test, male: $q_{(11)}=3.06, p=0.020$; female: $q_{(11)}=4.06$, $p=0.0035)$.

Choice latency (Fig. 4D) decreased when reinforcement was not guaranteed in male (Dunnett's test, 10,500 ppm vs baseline, 12.5\% block: $q_{(11)}=3.23, p=0.015 ; 6000$ ppm, $6.25 \%$ block: $\left.q_{(11)}=3.54, p=0.0085\right)$ and female rats $(10,500 \mathrm{ppm}$ vs baseline, 50\% block: $q_{(11)}=3.27, p=0.014 ; 12.5 \%$ block: $q_{(11)}=3.26, p=$ $0.014,6.25 \%$ block: $\left.q_{(11)}=3.79, p=0.0056\right)$. Interestingly, $10,500 \mathrm{ppm}$ toluene increased choice latency in male rats when risky reinforcement was guaranteed (Dunnett's test, vs baseline, 100\% block: $\left.q_{(11)}=2.95, p=0.024\right)$. Omissions (Fig. $4 E$ ) were reduced in male $\left(10,500 \mathrm{ppm}: q_{(11)}=3.25, p=0.0144 ; 6000\right.$ ppm: $\left.q_{(11)}=3.09, p=0.019\right)$, but not female rats (all $q_{(11)}<1.82$, $p>0.16)$.

Effect of toluene on in vivo mPFC activity measured using the genetically encoded calcium sensor GCaMP6f

Baseline activity

The activity of prelimbic mPFC neurons was measured by fiber photometry in rats injected with AAV1-CaMKII-GCaMP6f and exposed to air or toluene and $30 \mathrm{~min}$ of home-cage recovery (Fig. $5)$. Paired $t$ tests of average GCaMP6f responses revealed no difference in event frequency $\left(t_{(6)}=0.221, p=0.832\right)$, event amplitude $\left(t_{(6)}=0.342, p=0.744\right)$, event width $\left(t_{(6)}=1.41, p=\right.$ $0.209)$, or inter-event interval $\left(t_{(6)}=0.112, p=0.914\right)$.
mPFC activity tracks deliberation and outcome during probabilistic discounting

Figure $6 \mathrm{~A}$ illustrates the average GCaMP6f signal across all trials during the probabilistic discounting task in air-treated rats ( 8 rats, 1081 trials total). Visual inspection of these graphs revealed a peak of activity during deliberation, $\sim 1-2 \mathrm{~s}$ before lever press, and decreases in signal during outcome, 1-16 s following lever press. A one-way ANOVA revealed an effect of choice outcome on GCaMP6f signal $\left(F_{(1.377,9.638)}=37.9, p<0.0001\right.$; Fig. $6 B$, left $)$. This effect was due to differentiation between large/risky wins and small/safe wins (Sidak's post hoc, risky win vs safe win: $t_{(7)}=$ 4.27, $p=0.011$ ) as well as losses versus any win (risky loss vs safe win: $t_{(7)}=4.81, p=0.0058$; risky loss vs risky win: $t_{(7)}=8.001$, $p=0.0003$ ). Choice outcome also affected putative consumption as measured by time spent in the food well (Fig. 6B, right; one-way ANOVA, $\left.F_{(1.503,10.52)}=588, p<0.0001\right)$. This effect was also driven by differentiation between large/risky wins and small/safe wins (Sidak's post hoc, risky win vs safe win: $t_{(7)}=13.5, p<0.0001$ ) as well as losses vs any win (risky loss vs safe win: $t_{(7)}=29.5, p<0.0001$; risky loss vs risky win: $\left.t_{(7)}=28.5, p<0.0001\right)$.

$Z$-normalization of data during deliberation (Fig. 6C) revealed that activity increased relative to baseline (one-sample $t$ test vs baseline: before risky: $t_{(500)}=6.92, p<0.0001$; before safe: $t_{(522)}=6.71, p<0.0001$; data not shown). Traces were then sorted into forced-choice and free-choice trials. In forced-choice trials (Fig. 6Ci), there was a significant interaction between peak activity before lever press and behavior block (two-way ANOVA, upcoming choice $\times$ behavior block: $\left.F_{(4,433)}=5.37, p=0.0030\right)$. This was because of a relatively greater increase before risky choice during the $100 \%$ block (Sidak's test, $t_{(433)}=2.73, p=0.033$ ) and 

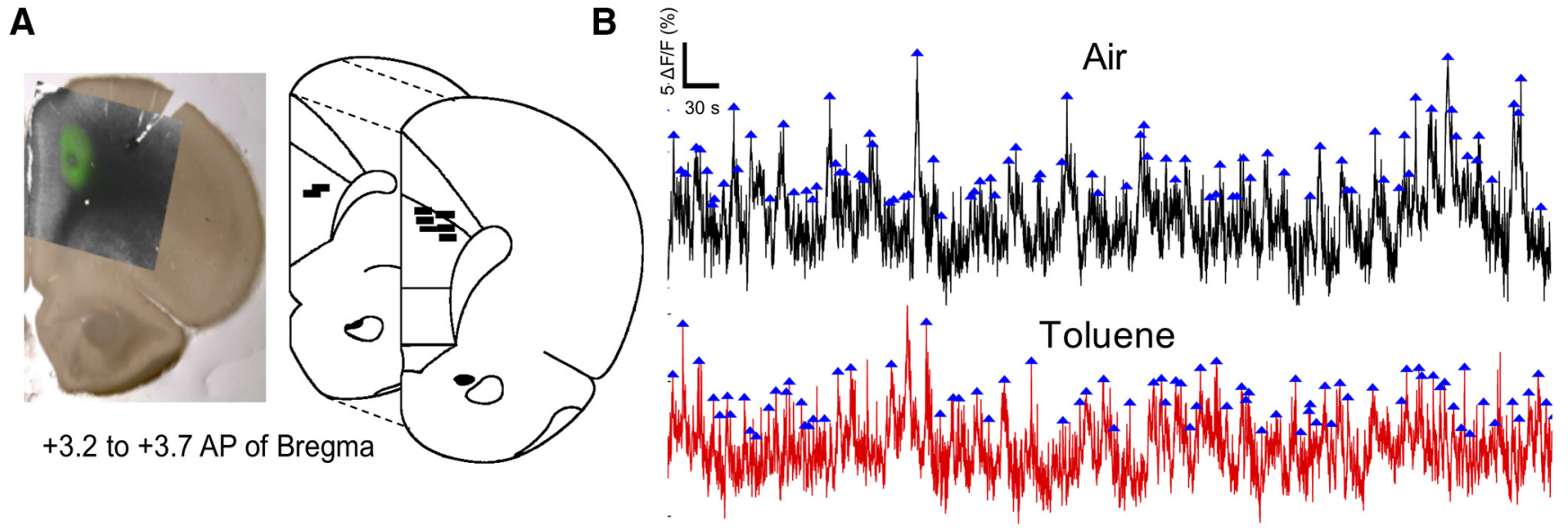

C

Event Frequency

D

Event Amplitude
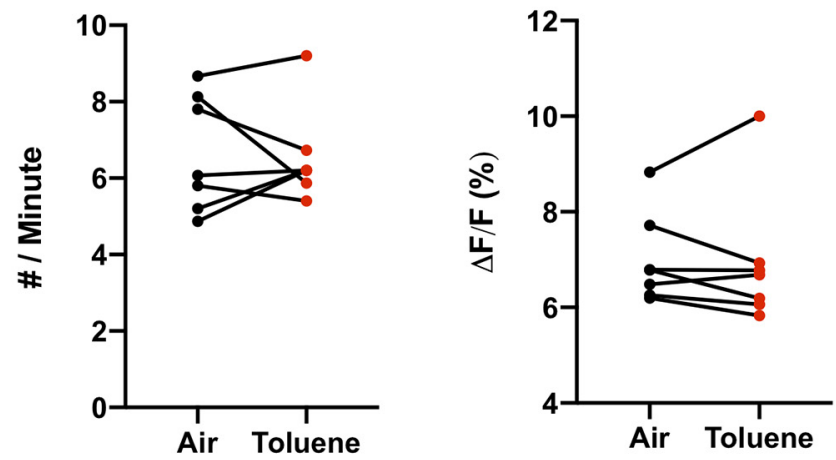

E

Event Width

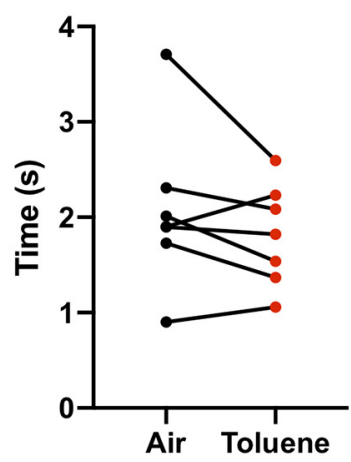

F
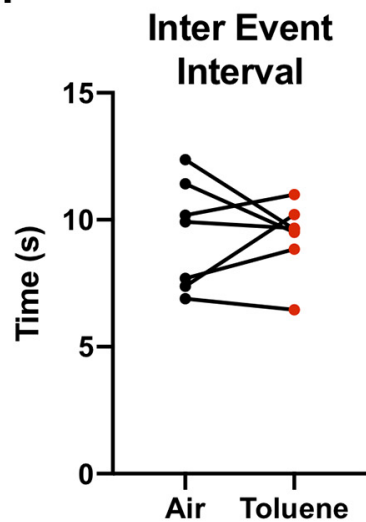

Figure 5. Basal prelimbic mPFC calcium activity is unaffected by acute toluene. Activity was measured in prelimbic mPFC neurons with fiber photometry in rats injected with AAV1-CaMKIIGCaMP6f and exposed to air or toluene $\boldsymbol{A}$, Exemplar viral expression (left) and fiber optic ferrule placement (right, black bars). $\boldsymbol{B}$, Representative 15 min photometry recording following air (black) or toluene (red) treatment with detected calcium peak (blue arrows). Paired comparison of (C) GCaMP6f event frequency, $(\boldsymbol{D})$ mean amplitude, $(\boldsymbol{E})$ mean width, and $(\boldsymbol{F})$ mean inter-event interval in toluene and control conditions in seven rats.

before safe choice during the $6.25 \%$ block $\left(t_{(433)}=3.06, p=0.012\right)$. The interaction between activity before lever press and behavior block was not present during free-choice trials (Fig. 6 Cii; $F_{(4,569)}=$ $0.550, p=0.70)$.

Toluene disrupts mPFC activity during deliberation and outcome Figure $7 A$ shows the average fluorescence changes across all trials during the probabilistic discounting task on toluene test days ( 8 rats, 1081 trials each). Like air-treated control days, these graphs show a peak of activity during deliberation and troughs during outcome (Fig. 7B). Further, A one-way ANOVA revealed an effect of choice outcome on GCaMP6f signal $\left(F_{(1.698,11.88)}=16.5\right.$, $p=0.0005)$. However, unlike controls, there was no differentiation between large/risky wins and small/safe wins (Sidak's post $h o c$, risky win vs safe win: $\left.t_{(7)}=0.05, p>0.9999\right)$. There was a distinction between GCaMP6f signal following losses versus wins (risky loss vs safe win: $t_{(7)}=4.56, p=0.0078$; risky loss vs risky win: $\left.t_{(7)}=4.48, p=0.0086\right)$.

Choice outcome also affected putative consumption as measured by time spent in the food well (Fig. $7 B$, right; one-way ANOVA, $\left.F_{(1.811,12.68)}=763, p<0.0001\right)$. This effect was also driven by differentiation between large/risky wins and small/safe wins as well as losses versus any win (all $t_{(7)}>17.9, p<0.0001$; Fig. $7 B)$.

$Z$-normalization of data during deliberation (Fig. 7C) revealed that $\mathrm{mPFC}$ activity increased relative to baseline (onesample $t$ test vs $0 \% \Delta \mathrm{F} / \mathrm{F}$, before risky: $t_{(424)}=6.24, p<0.0001$; before safe: $t_{(611)}=10.7 p<0.0001$; data not shown). Traces were then sorted into forced-choice and free-choice trials. Unlike control conditions, there was no interaction between activity before lever press and behavior block during forced-choice trials following toluene exposure (Fig. 7Ci; two-way ANOVA, $F_{(4,442)}=$ $1.48, p=0.21)$. Similar to control conditions, this interaction did not exist during free-choice trials (Fig. 6 Cii; $F_{(4,574)}=$ 0.264, $p=0.90)$.

Acute exposure to $10,500 \mathrm{ppm}$ toluene vapor $30 \mathrm{~min}$ before testing disrupted descending odds probabilistic discounting in rats expressing GCaMP6f in the mPFC (Fig. 8A-E). This included increased risky choice preference (Fig. 8A; two-way ANOVA, main effect of drug: $\left.F_{(1,7)}=11.6, p=0.011\right)$ and reduced loseshift behavior (Fig. $8 C$; paired $t$ test, $t_{(7)}=2.52, p=0.040$ ). Toluene also caused a slight, but significant reduction in consumption time (Fig. $8 F$, two-way ANOVA, main effect of treatment: $\left.F_{(1,21)}=4.43, p=0.048\right)$, an effect driven by consumption during large/risky wins (Sidak's post hoc, $t_{(21)}=2.83, p=0.030$ ) and not small/safe wins $\left(t_{(21)}=0.318, p=0.99\right)$ or risky losses $\left(t_{(21)}=0.501, p=0.96\right)$. Finally, we directly compared signal during deliberation (Fig. $8 G$ ) and outcome (Fig. 8H). mPFC activity increased in toluene exposed animals compared with air before a safe lever press (Fig. $8 G$; paired $t$ test, $t_{(7)}=2.38, p=$ $0.049)$ but not a risky lever press $\left(t_{(7)}=1.15, p=0.29\right)$. Toluene exposure resulted in a smaller $\mathrm{mPFC}$ activity trough compared with air following safe wins (Fig. $8 H ; t_{(7)}=2.80, p=0.027$ ) and 


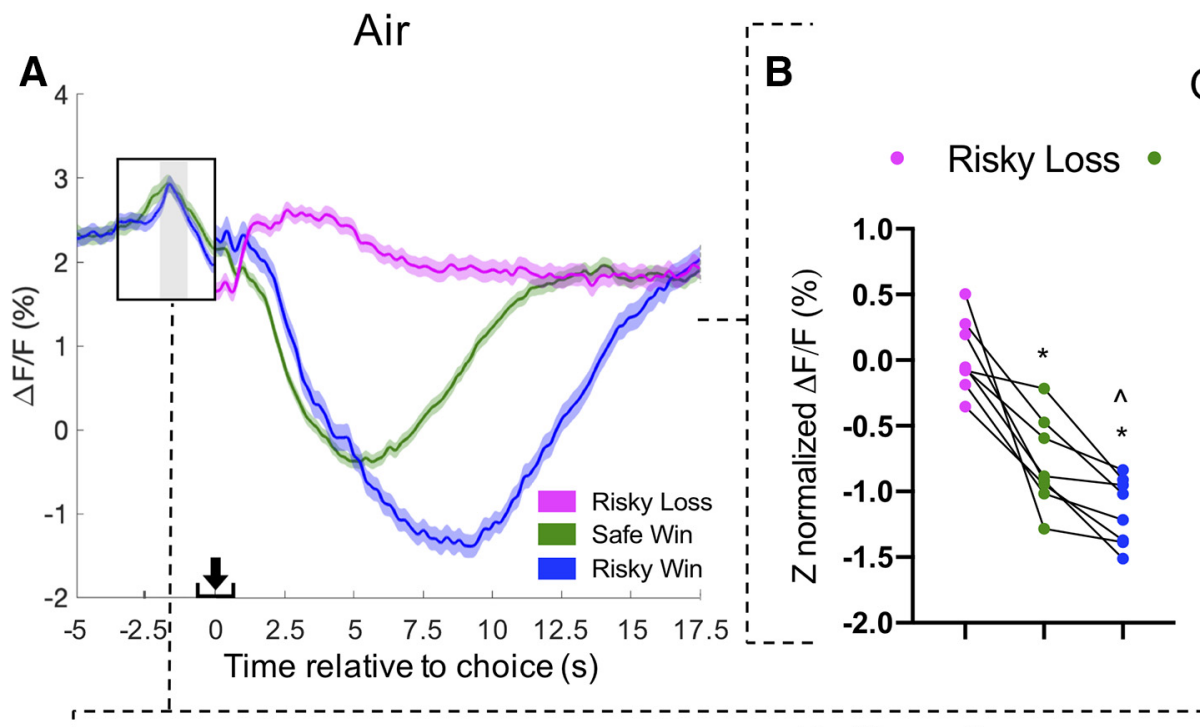

\section{Outcome}

\section{C i. Forced-Choice}
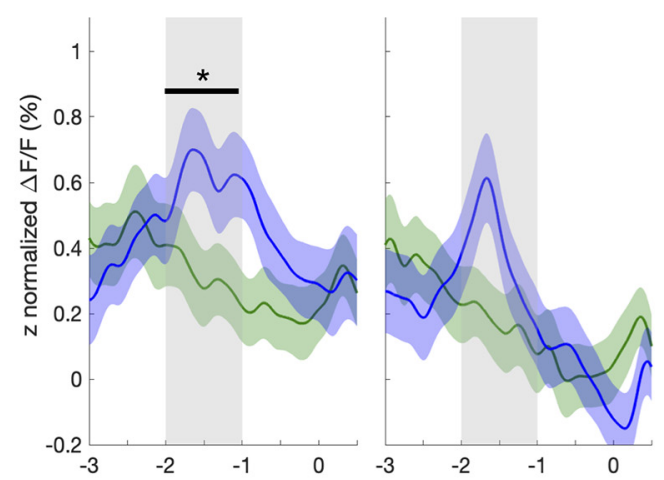

ii. Free-Choice

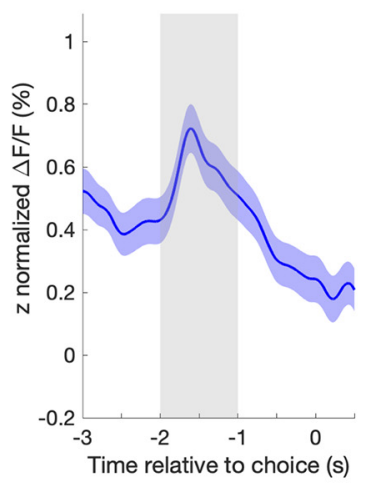

100

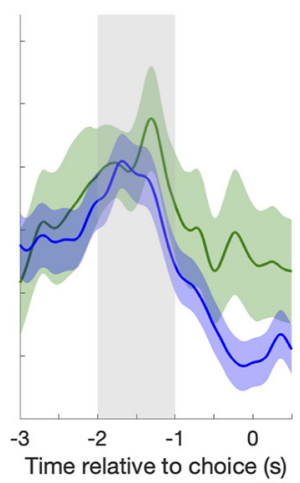

50

\section{Deliberation}
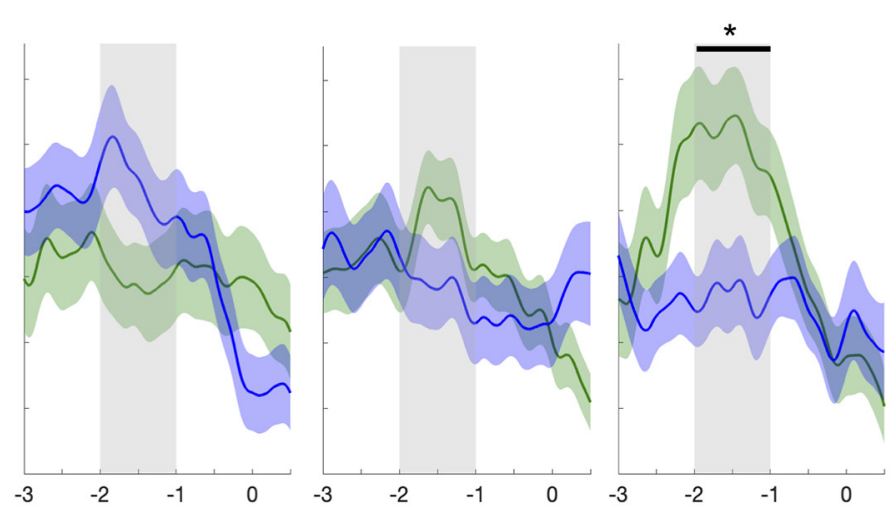

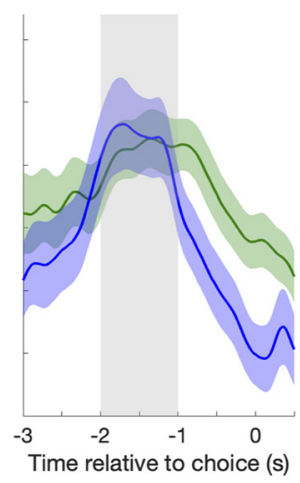

25

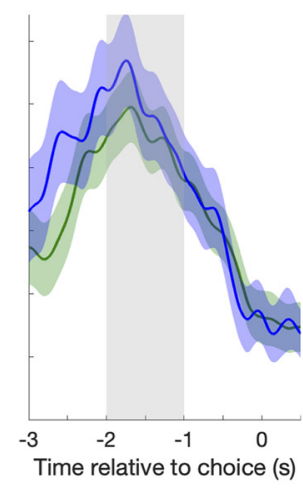

12.5

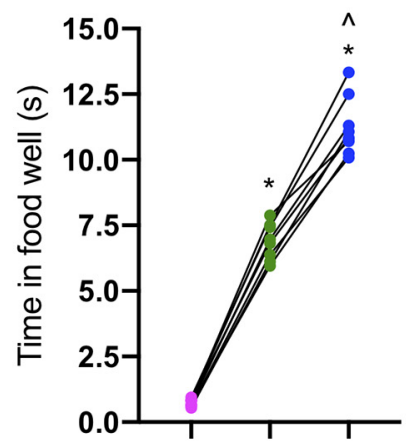

Prior to Safe Choice

Prior to Risky Choice

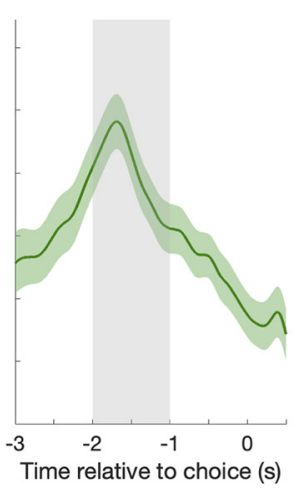

6.25

Probability of Risky Reward (\%)

Figure 6. PrL mPFC pyramidal activity tracks choice tracks choice selection and outcome during probabilistic discounting. $A$, Aggregate calcium response (8 rats; 1081 trials) during entire probabilistic discounting task from air-treated controls. Lines represent average $\pm \mathrm{SEM} \Delta F / F$ for safe choice/win (green), risky choice/win (blue), risky loss (pink). An increase in calcium activity was detected during deliberation, $\sim 1.5$ s before choice (shaded column throughout figure). $\boldsymbol{B}$, Average Z-normalized $\Delta F / F$ (left) and consumption time (right) during choice outcome for each rat with paired comparison: safe win versus risky win, $\wedge p<0.05$; risky loss versus safe win or risky win, ${ }^{*} p<0.05$. C, Traces during deliberation were sorted on probability of rewarded risky choice (i.e., 100 , $50,25,12.5$, and $6.25 \%$ ) and choice type (i.e., free and forced); aggregate Z-normalized mean $\pm S E M \Delta F / F$ with average peaks summarized (right). Average calcium response during forced-choice (Ci; 443 traces, 8 rats) and free-choice (Cii; 560 traces, 8 rats). Summary traces exclude instances with $<10$ traces across $<3$ rats. Sidak's multiple comparison of mean value, safe versus risky choice, ${ }^{*} p<0.05$. Arrow indicates moment of lever press. 


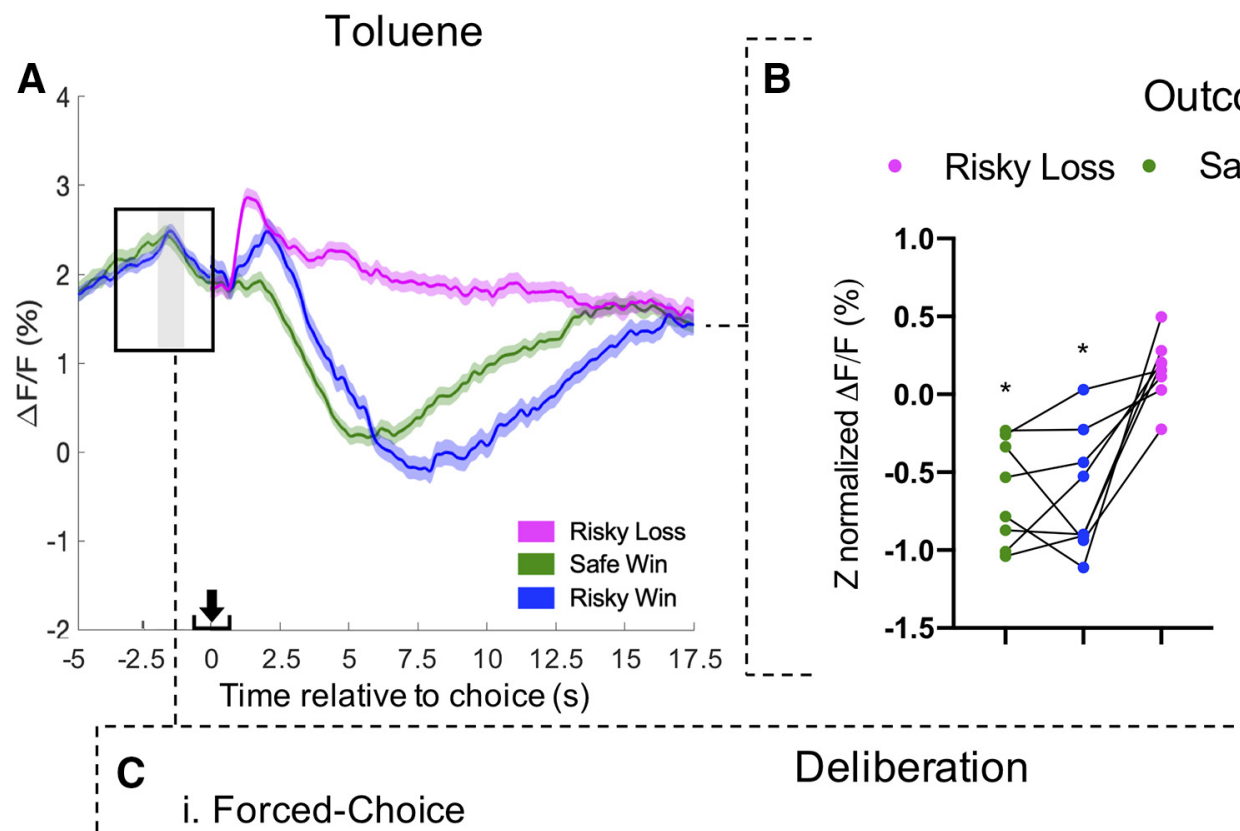

\section{Outcome}
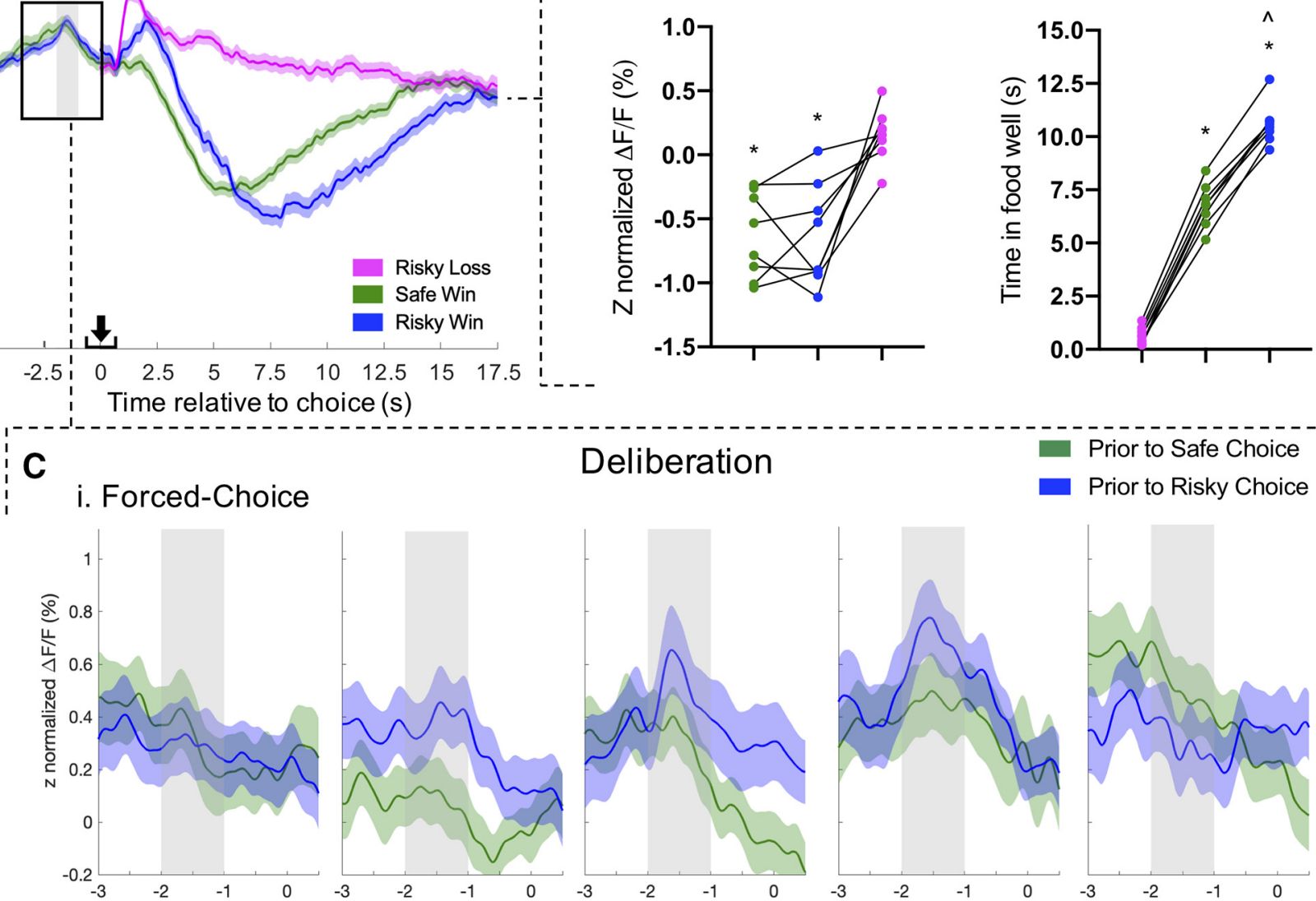

ii. Free-Choice

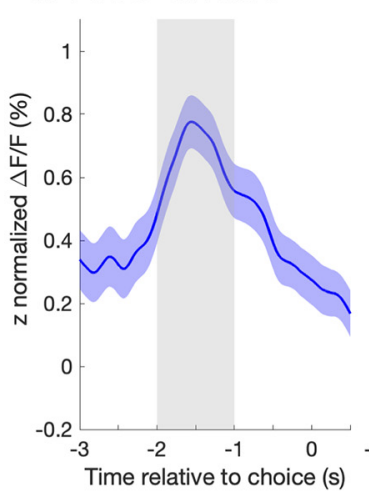

100

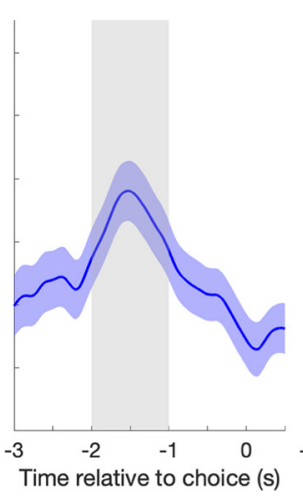

50

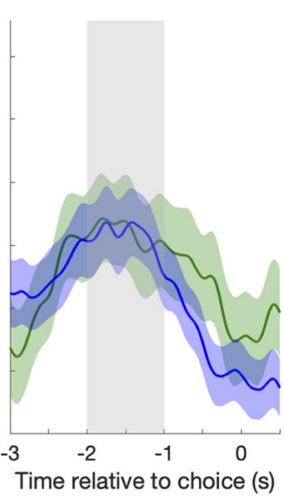

25

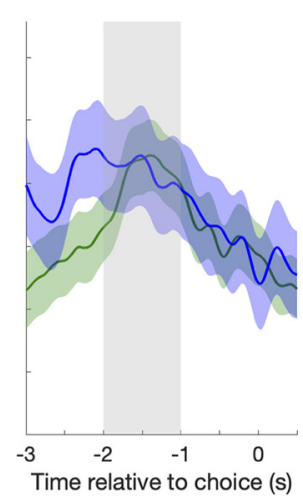

12.5
Prior to Safe Choice

- Prior to Risky Choice

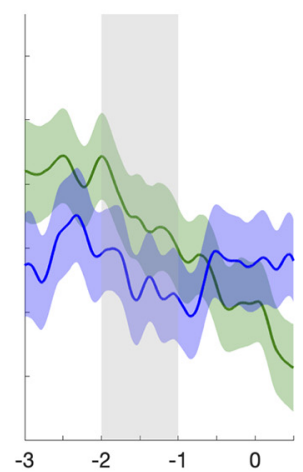

Probability of Risky Reward (\%)

Figure 7. Toluene disrupts PrL mPFC pyramidal activity responsible for predicting preferred choice and encoding consumption during probabilistic discounting. A, Aggregate calcium response (8 rats; 1081 trials) during entire probabilistic discounting task on toluene-treated test days. Lines represent average \pm SEM $\Delta F / F$ for safe choice/win (green), risky choice/win (blue), and risky loss (pink). An increase in calcium activity was detected during deliberation, $\sim 1.5 \mathrm{~s}$ before choice (shaded column throughout figure). $B$, Average Z-normalized $\Delta F / F$ (left) and consumption time (right) during choice outcome for each rat with paired comparison: safe win versus risky win, $\wedge p<0.05$; risky loss versus safe win or risky win, ${ }^{*} p<0.05$. C, Traces during deliberation were sorted on probability of rewarded risky choice (i.e., $100,50,25,12.5$, and $6.25 \%$ ) and choice type (i.e., free and forced); aggregate Z-normalized mean \pm SEM $\Delta F / F$ ). Average calcium response during forced-choice (Ci; 452 traces, 8 rats) and free-choice (Cii; 566 traces, 8 rats). Summary traces exclude instances with $<10$ traces across $<3$ rats. Paired $t$ tests ${ }^{*} p<0.05,{ }^{* *} p<0.01$. Arrow indicates moment of lever press. 
A

Probabilistic Discounting

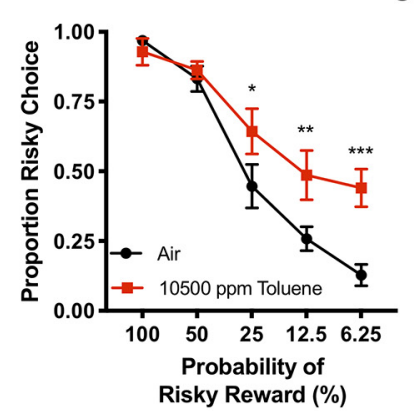

F

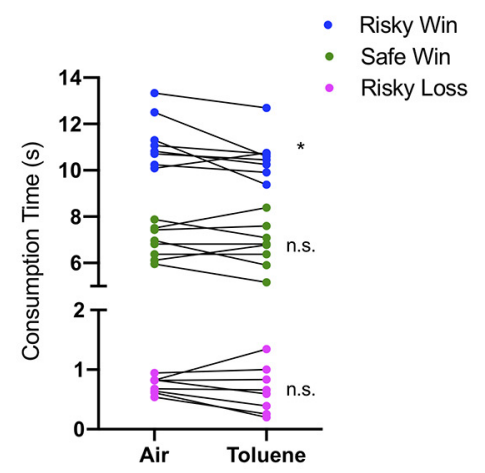

H

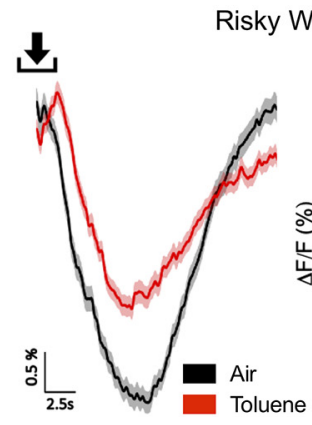

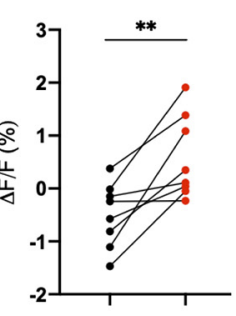

B

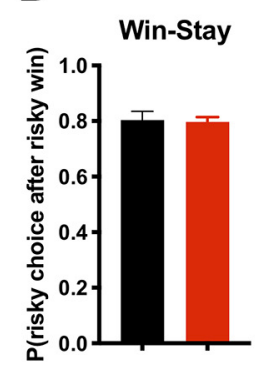

G

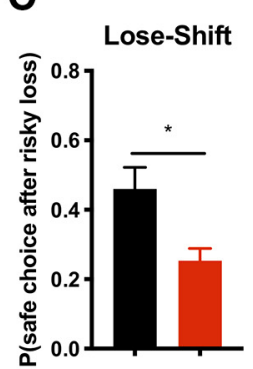

D

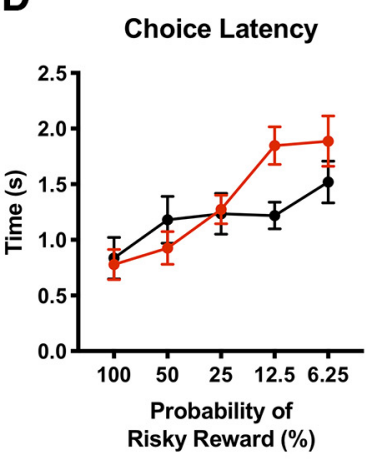

E

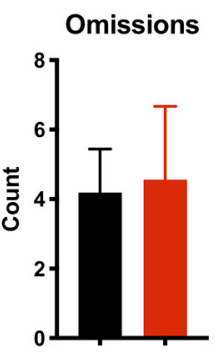

Deliberation
Prior to Safe Choice

Prior to Risky Choice

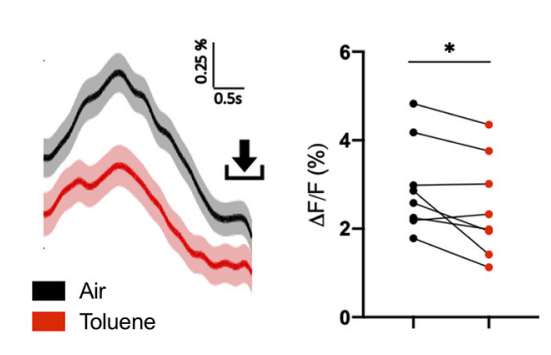

Outcome

Safe Win

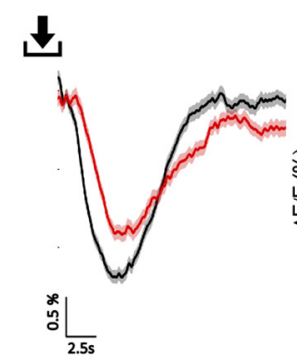

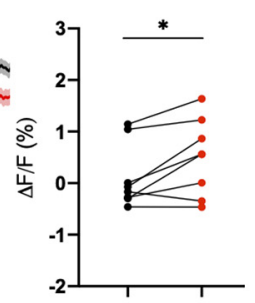
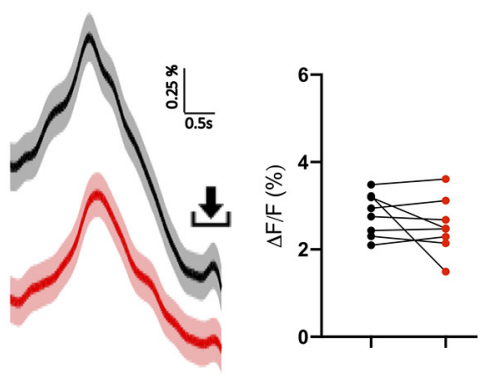

Risky Loss

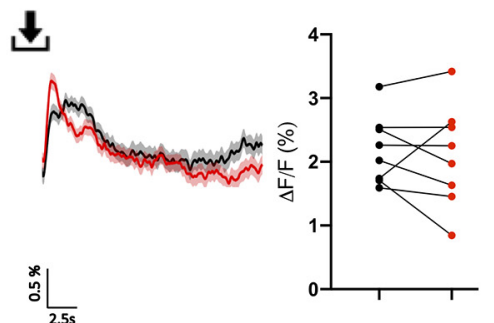

Figure 8. Probabilistic discounting during fiber photometry recordings following acute air or toluene exposure. Fiber-tethered rodents expressing GCaMP6f performed the probabilistic discounting task following exposure to toluene and air. $A$, Proportion of risky choice within each probability block following acute exposure to air or 10,500 ppm toluene. $\boldsymbol{B}, C$, Choice strategy across all trials. Win-stay $(\boldsymbol{B})$ indicates choice of risky lever after risky win, whereas lose-shift $(\boldsymbol{C})$ indicates choice of safe lever after risky loss. $\boldsymbol{D}$, Time to choice selection within each probability block. Omissions across all trials $(\boldsymbol{E})$ indicate no lever press within $10 \mathrm{~s} \mathrm{time} \mathrm{period.} \boldsymbol{F}$, Paired comparison of consumption time on air versus toluene treatment days across all outcomes. $\boldsymbol{G}$, Mean $\Delta F / F \pm S E M$ for all eight rats on air versus toluene treatment days during deliberation: before safe choice (air, 501 traces; toluene, 425 traces) and before risky choice (air, 523 traces; toluene, 610 traces) with paired comparison summaries (right). $\boldsymbol{H}$, Mean $\Delta F / F \pm$ SEM during choice outcome: during a risky win (air, 501 traces; toluene, 425 traces), during a safe win (air, 264 traces; toluene, 282 traces), and during risky loss (air, 276 traces; toluene, 330 traces) with paired-comparison summaries (right). Data shown are mean \pm SEM; $n=8$; two-way ANOVAs with Sidak's post hoc, n.s., Not significant; ${ }^{*} p<0.05,{ }^{* *} p<0.01,{ }^{* * *} p<0.001$. Arrows indicate moment of lever press.

risky wins $\left(t_{(7)}=3.96, p=0.0055\right)$, but not risky losses $\left(t_{(7)}=\right.$ $0.536, p=0.61)$.

\section{Discussion}

Acute toluene impairs probabilistic discounting

To understand how the abused inhalant toluene affects risk/reward decision-making, we exposed animals highly trained in the probabilistic discounting task to air or two levels of toluene vapor. We found a dose-dependent effect of toluene on risky choice preference in both male and female rats. Toluene increased risky choice preference when the initial expected value of the risky lever was high (descending odds task), but decreased risky choice preference when the initial expected value of the risky lever was low (ascending odds task). These effects were driven primarily by a perturbation in sensitivity to negative feedback, although a reduction in positive feedback sensitivity was also observed. We interpret these findings as a toluene-induced failure to update expected values, resulting in behavioral inflexibility as the task progressed and reward probabilities changed.

The alterations in choice and response latencies induced by toluene are similar to those induced by of amphetamine (St. Onge and Floresco, 2009; St. Onge et al., 2010), one of only two known drugs for which toluene serves as a discriminative stimulus (Bowen, 2006). As first suggested by St. Onge et al. (2010), enhanced $\mathrm{mPFC}$ dopamine signaling might be the cause of amphetamine-induced discounting impairments because (1) increasing dopamine perturbs complex cognitive functions mediated by the mPFC, (2) pharmacologically silencing the mPFC 
caused the same procedural-dependent effects, and (3) mPFC dopamine levels track reward rates during probabilistic discounting (St. Onge and Floresco, 2010; St. Onge et al., 2010, 2012b). Interfering with this dopamine signal might disrupt the ability to accurately encode reward value and/or act on choice valuation, resulting in more static patterns of choice. A similar mechanism should be considered for toluene, because it is known to increase extracellular levels of dopamine in the mPFC (Gerasimov et al., 2003; Koga et al., 2008) and as described in these studies, alters mPFC activity during probabilistic discounting. One caveat is that pharmacological activation of dopamine D2, but not D1, receptors in the MPFC only serve to decrease risky choice preference during probabilistic discounting (St. Onge et al., 2011). Interestingly however, simultaneous stimulation of mPFC D2 receptors while pharmacologically silencing the basolateral amygdala causes the same procedural-dependent effects on probabilistic discounting as acute toluene exposure (Jenni et al., 2017). Future studies on the effect of toluene on complex cognitive behaviors should take this circuit into consideration.

The increase in task engagement (i.e., decreased latency and omissions) following toluene exposure was not universal across sex or task type (ascending or descending). Toluene's effects on these measures is likely more to do with differences in the task and how these differences affect each sex than a general impairment in performance. In fact, inactivating the mPFC causes a slight increase in latency during safe-optimal trials of descending odds probabilistic discounting (St. Onge and Floresco, 2010). Furthermore, omissions during probabilistic discounting are unaffected by mPFC inactivation or disconnection of mPFCnucleus accumbens circuitry (St. Onge et al., 2012a). On the other hand, treatment with the adrenergic autoreceptor antagonist yohimbine (Montes et al., 2015) has been shown to produce an effect on choice behavior during probabilistic discounting that is similar to that of toluene reported here while at the same time reducing response latencies. Thus, although not currently known, toluene may simultaneously impair shifts in choice bias and enhance task engagement via alterations in catecholaminergic signaling.

\section{Effect of adolescent toluene exposure on future probabilistic discounting}

Drug abuse during adolescence can lead to future cognitive impairments, substance abuse issues, and mood disorders. In fact, rodents show increased risk preference during probabilistic discounting following chronic adolescent alcohol exposure, despite a protracted abstinence (Boutros et al., 2015). Unlike ethanol, we found that adult rats with a history of toluene exposure during adolescence performed the risk task similarly to air-treated controls. Some transient increases in choice latency were observed during training that could be the result of instrumental learning deficits observed despite abstinence from toluene (Dick et al., 2014; Braunscheidel et al., 2017). Another non-mutually exclusive possibility is that increased anxiety during toluene withdrawal (Bowen et al., 2018) led to increased indecisiveness, and thus deliberation time. This notion agrees with the increased choice latency observed following acute stress or infusions of corticotropin releasing factor effort-discounting tasks (Shafiei et al., 2012; Bryce and Floresco, 2016). Finally, although rats received multiple toluene exposures during adolescence, the experience was over a relatively brief time period $(5 \mathrm{~d})$. A more extensive exposure period like that used by Boutros et al. (2015) might cause a greater effect on the measured parameters.

In this study, an acute challenge with 10,5000 ppm toluene in adult rats with a history of toluene exposure during adolescence produced similar alterations in probabilistic discounting, loseshift behavior, and choice latency as those only exposed to toluene as adults. However, we did not observe any increase in win-stay behavior in the combined adolescent/adult exposed animals. Interestingly, the lower dose of toluene failed to produce an appreciable change in discounting but did increase winstay behavior in both male and female rats. This combination of sensitization to the reward-promoting effects of toluene at lower doses with simultaneous desensitization to cognitive impairments could contribute to inhalant relapse despite protracted abstinence.

\section{mPFC calcium activity encodes information about upcoming choice and outcome}

Neuronal activity within the MPFC is critical for tasks involving behavioral flexibility (Birrell and Brown, 2000; Marquis et al., 2007; Floresco et al., 2008) including probabilistic discounting (St. Onge and Floresco, 2010). In the present study, we used in vivo fiber photometry to investigate the importance of mPFC activity on probabilistic discounting with temporal specificity and to provide physiological evidence for a mPFC-dependent mechanism of toluene-induced deficits on probabilistic discounting. We observed increases in mPFC activity before any freechoice press, independent of the actual expected value of that press. This is consistent with previous reports showing that the firing rate of $\mathrm{mPFC}$ neurons increases before an action that is intended to generate reward (Sul et al., 2010). Data from forcedchoice trials indicate that this signal does not simply predict any action that might generate reward. Rather, increases in mPFC activity appeared to flexibly shift from predicting forced risky choice to forced safe choice throughout the session. Because this pattern reflects the theoretical optimal choice to maximize expected outcome (risky early when risky reward probabilities are high, safe late when risky reward probabilities are low) we interpret this as a "preferred action" signal. This interpretation is similar to the recently described "outcome-prediction" activity discovered in mPFC neurons that fire specifically once an attentional set-shift is completed (Del Arco et al., 2017).

In this study, we found a prominent decrease in mPFC calcium activity during rewarded outcome that was correlated with reward magnitude in air-treated animals. At first take, these data seem in stark contrast to many reports of increased mPFC electrical activity during reward outcome and consumption (McCoy and Platt, 2005; Horst and Laubach, 2013; Petykó et al., 2015; Del Arco et al., 2017). However, these studies refer to a very short time scale following reward delivery $(0-2 \mathrm{~s})$ compared with the duration of reward consumption during which we recorded $\mathrm{mPFC}$ calcium transients $(0-20 \mathrm{~s})$. Increases in mPFC spiking is tightly linked with initiation of consumption behavior (i.e., licking), activity which desensitizes over time (Horst and Laubach, 2013). Further, a majority of mPFC activity during outcome switches from excitatory to inhibitory $\sim 1.5 \mathrm{~s}$ post reward delivery (Del Arco et al., 2017). Combined, these factors could explain the sustained dip in mPFC calcium activity we observed during reward consumption and might represent portions of the brain's executive functions "going off-line" while engaging in a habitual or automatic behavior. It is clear however that this is not a global effect because Passecker et al. (2019) recently identified two dorsal mPFC ensembles that actively relay information about the value of the current reward, and influence upcoming choice. 


\section{Effect of toluene on mPFC activity during probabilistic discounting}

Toluene disrupted flexible risk/reward decision-making in a manner similar to pharmacological inactivation of the mPFC (St. Onge and Floresco, 2010). As such, it is possible that the effects of toluene were driven by a general suppression of PFC in neural activity. Yet, when we measured baseline mPFC calcium activity in animals treated with the same toluene exposure protocol as during behavioral tests, we failed to detect any significant differences in magnitude or frequency of spontaneous calcium transients compared with air-treated controls. Thus, although it is clear that toluene can disrupt mPFC function, this does not appear to result from a global reduction in neural activity, but rather, may be mediated by disruptions in task-dependent patterns of mPFC activity.

mPFC activity increased during epochs before lever selection (i.e., deliberation). Acute administration of toluene blunted this increase, an effect that was driven by activity specifically before an upcoming safe, but not risky choice when collapsed across all trials. However, whereas increases in mPFC activity shift from pre-risky to pre-safe press during forced-choice trials in airtreated controls, activity in toluene-treated animals display a slightly different activity profile: (1) activity before either lever press did not increase in the first probability block, and (2) the shift in activity from pre-risky to pre-safe was disrupted. Further, toluene-treated animals still show strong increases before safe lever presses in free-choice trials. Together, these results suggest a toluene-induced failure to recognize changes in relative value of both levers as the task progresses rather than a nonspecific reduction in signaling preceding a low-risk decision.

As with air-treated controls, toluene exposed rats showed a sustained dip in mPFC calcium activity across all rewarded trials. This dip was mitigated by toluene during both safe and risky wins, suggesting reduced $\mathrm{mPFC}$ silencing during consumption. Further, mPFC activity during a safe win was indistinguishable from a risky win following toluene treatment. Although this could be explained by a general deficit in reward magnitude discrimination, toluene-treated animals did show appropriate discrimination (i.e., large reward preference) when the risky lever was reinforced $100 \%$ of the time. It is more likely that the deficit reflects impaired function of a subpopulation of neurons responsible for updating current outcome to influence future decision, like those recently discovered by Passecker et al. (2019). One such subpopulation might be deep-layer mPFC neurons projecting to the nucleus accumbens core, that are hypo-excitable following toluene treatment (Wayman and Woodward, 2018). Alterations in the activity of these neurons by toluene could explain the drug's effect on mPFC activity during choice outcome.

\section{Sex differences in baseline probabilistic discounting}

Sex differences have been reported in other preclinical models of decision-making involving risk (for review, see Orsini and Setlow, 2017). In these studies, we found that male and female rats acquired similar levels of probabilistic discounting, largely consistent with a recent report (Westbrook et al., 2018). Males and females were similarly sensitive to recent positive and negative feedback as measured by win-stay and lose-shift behavior, respectively. Females made much quicker decisions and fewer omissions than males. It is possible that females were hungrier than males during task performance, leading higher relative value of the food reward and thus greater task engagement. However, the food-restriction protocol whereby animals are limited based on their individual free-feeding weight should control for this pos- sibility. The sex differences in task-engagement are in stark contrast to probabilistic discounting under risk of footstock, where females omit significantly more than males (Orsini et al., 2016). This indicates that females and males use different strategies regarding the decision to engage a risky situation when the punishment is neutral (reward omission) compared with aversive (foot shock). These sex differences should be taken into consideration when testing the effects of other experimental factors on probabilistic discounting.

\section{Conclusion}

The studies herein describe the effect of abuse levels of toluene vapor exposure on risk/reward decision-making and strongly implicate mPFC dysfunction as a source of impaired flexible adjustments in choice biases. This deficit might be caused by perturbed task-related activity in subpopulations of projection specific mPFC neurons (e.g., BLA-projecting D2+ or nucleus accumbens core-projecting deep-layer pyramidal neurons) failing to integrate reward magnitude information to inform and/or execute future decisions. Future studies should attempt to identify these populations with molecular- and circuit-level specificity and how they are specifically impaired by toluene.

\section{References}

Balster RL, Cruz SL, Howard MO, Dell CA, Cottler LB (2009) Classification of abused inhalants. Addiction 104:878-882.

Batis JC, Hannigan JH, Bowen SE (2010) Differential effects of inhaled toluene on locomotor activity in adolescent and adult rats. Pharmacol Biochem Behav 96:438-448.

Baydas G, Ozveren F, Akdemir I, Tuzcu M, Yasar A (2005) Learning and memory deficits in rats induced by chronic thinner exposure are reversed by melatonin. J Pineal Res 39:50-56.

Beckley JT, Woodward JJ (2011) The abused inhalant toluene differentially modulates excitatory and inhibitory synaptic transmission in deep-layer neurons of the medial prefrontal cortex. Neuropsychopharmacology 36 : 1531-1542.

Birrell JM, Brown VJ (2000) Medial frontal cortex mediates perceptual attentional set shifting in the rat. J Neurosci 20:4320-4324.

Boutros N, Semenova S, Liu W, Crews FT, Markou A (2015) Adolescent intermittent ethanol exposure is associated with increased risky choice and decreased dopaminergic and cholinergic neuron markers in adult rats. Int J Neuropsychopharmacol 18:pyu003.

Bowen SE (2006) Increases in amphetamine-like discriminative stimulus effects of the abused inhalant toluene in mice. Psychopharmacology 186: 517-524.

Bowen SE, Hannigan JH, Davidson CJ, Callan SP (2018) Abstinence following toluene exposure increases anxiety-like behavior in mice. Neurotoxicol Teratol 65:42-50.

Brady AM, Floresco SB (2015) Operant procedures for assessing behavioral flexibility in rats. J Vis Exp 96:e52387.

Braunscheidel KM, Gass JT, Mulholland PJ, Floresco SB, Woodward JJ (2017) Persistent cognitive and morphological alterations induced by repeated exposure of adolescent rats to the abused inhalant toluene. Neurobiol Learn Mem 144:136-146.

Brouette T, Anton R (2010) Clinical review of inhalants. Am J Addict 10:794.

Bryce CA, Floresco SB (2016) Perturbations in effort-related decisionmaking driven by acute stress and corticotropin-releasing factor. Neuropsychopharmacology 41:2147-2159.

Bukowski JA (2001) Review of the epidemiological evidence relating toluene to reproductive outcomes. Regul Toxicol Pharmacol 33:147-156.

Del Arco A, Park J, Wood J, Kim Y, Moghaddam B (2017) Adaptive encoding of outcome prediction by prefrontal cortex ensembles supports behavioral flexibility. J Neurosci 37:8363-8373.

Dick AL, Axelsson M, Lawrence AJ, Duncan JR (2014) Specific impairments in instrumental learning following chronic intermittent toluene inhalation in adolescent rats. Psychopharmacology 231:1531-1542.

Dingwall KM, Maruff P, Fredrickson A, Cairney S (2011) Cognitive recov- 
ery during and after treatment for volatile solvent abuse. Drug Alcohol Depend 118:180-185.

Floresco SB, Block AE, Tse MT (2008) Inactivation of the medial prefrontal cortex of the rat impairs strategy set-shifting, but not reversal learning, using a novel, automated procedure. Behav Brain Res 190:85-96.

Furlong TM, Duncan JR, Corbit LH, Rae CD, Rowlands BD, Maher AD, Nasrallah FA, Milligan CJ, Petrou S, Lawrence AJ, Balleine BW (2016) Toluene inhalation in adolescent rats reduces flexible behaviour in adulthood and alters glutamatergic and GABAergic signalling. J Neurochem 139:806-822.

Gerasimov MR, Collier L, Ferrieri A, Alexoff D, Lee D, Gifford AN, Balster RL (2003) Toluene inhalation produces a conditioned place preference in rats. Eur J Pharmacol 477:45-52.

Ghods-Sharifi S, St. Onge JR, Floresco SB (2009) Fundamental contribution by the basolateral amygdala to different forms of decision making. J Neurosci 29:5251-5259.

Gigengack R (2014) “My body breaks. I take solution.” Inhalant use in Delhi as pleasure seeking at a cost. Int J Drug Policy 25:810-818.

Gmaz JM, Yang L, Ahrari A, McKay BE (2012) Binge inhalation of toluene vapor produces dissociable motor and cognitive dysfunction in water maze tasks. Behav Pharmacol 23:669-677.

Horst NK, Laubach M (2013) Reward-related activity in the medial prefrontal cortex is driven by consumption. Front Neurosci 7:56.

Howard MO, Balster RL, Cottler LB, Wu LT, Vaughn MG (2008) Inhalant use among incarcerated adolescents in the united states: prevalence, characteristics, and correlates of use. Drug Alcohol Depend 93:197-209.

Huerta-Rivas A, López-Rubalcava C, Sánchez-Serrano SL, Valdez-Tapia M, Lamas M, Cruz SL (2012) Toluene impairs learning and memory, has antinociceptive effects, and modifies histone acetylation in the dentate gyrus of adolescent and adult rats. Pharmacol Biochem Behav 102:48 -57.

Jenni NL, Larkin JD, Floresco SB (2017) Prefrontal dopamine D 1 and D 2 receptors regulate dissociable aspects of decision making via distinct ventral striatal and amygdalar circuits. J Neurosci 37:6200-6213.

Johnston LD, Malley PM. O, Miech RA, Bachman JG, Schulenberg JE (2018) Monitoring the Future national survey results on drug use: 1975-2017. Ann Arbor: Institute for Social Research, University of Michigan.

Koga Y, Higashi S, Kawahara H, Ohsumi T (2007) Toluene inhalation increases extracellular noradrenaline and dopamine in the medial prefrontal cortex and nucleus accumbens in freely-moving rats. J Kyushu Dent Soc 61:39-54.

Lerner TN, Shilyansky C, Davidson TJ, Evans KE, Beier KT, Zalocusky KA, Crow AK, Malenka RC, Luo L, Tomer R, Deisseroth K (2015) Intactbrain analyses reveal distinct information carried by SNc dopamine subcircuits. Cell 162:635-647.

Marín-Navarrete R, Toledo-Fernández A, Villalobos-Gallegos L, Pérez-López A, Medina-Mora ME (2018) Neuropsychiatric characterization of individuals with inhalant use disorder and polysubstance use according to latent profiles of executive functioning. Drug Alcohol Depend 190:104-111.

Marquis JP, Killcross S, Haddon JE (2007) Inactivation of the prelimbic, but not infralimbic, prefrontal cortex impairs the contextual control of response conflict in rats. Eur J Neurosci 25:559-566.

McCoy AN, Platt ML (2005) Expectations and outcomes: decision-making in the primate brain. J Comp Physiol A Neuroethol Sens Neural Behav Physiol 191:201-211.

Montes DR, Stopper CM, Floresco SB (2015) Noradrenergic modulation of risk/reward decision making. Psychopharmacology 232:2681-2696.

Montes S, Solís-Guillén RDC, García-Jácome D, Páez-Martínez N (2017) Environmental enrichment reverses memory impairment induced by toluene in mice. Neurotoxicol Teratol 61:7-16.

Orsini CA, Setlow B (2017) Mini-review sex differences in animal models of decision making. J Neurosci Res 95:260-269.
Orsini CA, Willis ML, Gilbert RJ, Bizon JL, Setlow B (2016) Sex differences in a rat model of risky decision making. Behav Neurosci 130:50-61.

Passecker J, Mikus N, Malagon-Vina H, Anner P, Dimidschstein J, Fishell G, Dorffner G, Klausberger T (2019) Activity of prefrontal neurons predict future choices during gambling. Neuron 101:152-164.e7.

Petykó Z, Gálosi R, Tóth A, Máté K, Szabó I, Szabó I, Karádi Z, Lénárd L (2015) Responses of rat medial prefrontal cortical neurons to Pavlovian conditioned stimuli and to delivery of appetitive reward. Behav Brain Res 287:109-119.

Scott KD, Scott AA (2014) Adolescent inhalant use and executive cognitive functioning. Child Care Health Dev 40:20-28.

Shafiei N, Gray M, Viau V, Floresco SB (2012) Acute stress induces selective alterations in cost/benefit decision-making. Neuropsychopharmacology $37: 2194-2209$.

St. Onge JR, Floresco SB (2009) Dopaminergic modulation of risk-based decision making. Neuropsychopharmacology 34:681-697.

St. Onge JR, Floresco SB (2010) Prefrontal cortical contribution to riskbased decision making. Cereb Cortex 20:1816-1828.

St. Onge JR, Chiu YC, Floresco SB (2010) Differential effects of dopaminergic manipulations on risky choice. Psychopharmacology 211:209-221.

St. Onge JR, Abhari H, Floresco SB (2011) Dissociable contributions by prefrontal D 1 and D 2 receptors to risk-based decision making. J Neurosci 31:8625-8633.

St. Onge JR, Stopper CM, Zahm DS, Floresco SB (2012a) Separate prefrontal-subcortical circuits mediate different components of riskbased decision making. J Neurosci 32:2886-2899.

St. Onge JR, Ahn S, Phillips AG, Floresco SB (2012b) Dynamic fluctuations in dopamine efflux in the prefrontal cortex and nucleus accumbens during risk-based decision making. J Neurosci 32:16880-16891.

Stopper CM, Floresco SB (2011) Contributions of the nucleus accumbens and its subregions to different aspects of risk-based decision making. Cogn Affect Behav Neurosci 11:97-112.

Stopper CM, Floresco SB (2014) What's better for me? Fundamental role for lateral habenula in promoting subjective decision biases. Nat Neurosci 17:33-35.

Stopper CM, Green EB, Floresco SB (2014) Selective involvement by the medial orbitofrontal cortex in biasing risky, but not impulsive, choice. Cereb Cortex 24:154-162.

Sul JH, Kim H, Huh N, Lee D, Jung MW (2010) Distinct roles of rodent orbitofrontal and medial prefrontal cortex in decision making. Neuron 66:449-460.

Takagi M, Lubman DI, Cotton S, Fornito A, Baliz Y, Tucker A, Yücel M (2011) Executive control among adolescent inhalant and cannabis users. Drug Alcohol Rev 30:629-637.

Wayman WN, Woodward JJ (2018) Exposure to the abused inhalant toluene alters medial prefrontal cortex physiology. Neuropsychopharmacology 43:912-924.

Westbrook SR, Hankosky ER, Dwyer MR, Gulley JM (2018) Age and sex differences in behavioral flexibility, sensitivity to reward value, and risky decision-making. Behav Neurosci 132:75-87.

Wu LT, Howard MO (2007) Psychiatric disorders in inhalant users: results from the national epidemiologic survey on alcohol and related conditions. Drug Alcohol Depend 88:146-155.

Wu LT, Ringwalt CL (2006) Inhalant use and disorders among adults in the united states. Drug Alcohol Depend 85:1-11.

Yuncu Z, Zorlu N, Saatcioglu H, Basay B, Basay O, Zorlu PK, Kurtgoz P, Kitis O, Gelal F (2015) Neurotoxicology and teratology abnormal white matter integrity and impairment of cognitive abilities in adolescent inhalant abusers. Neurotoxicol Teratol 47:89-95. 